\title{
IIIVSPIII \\ Tailored Polyethylene Nanocomposite Sealants: Broad-Range Peelable Heat-Seals Through Designed Filler/Polymer Interfaces
}

\author{
Jinguo Zhang ${ }^{\mathrm{a}, \mathrm{b}}$, Evangelos Manias ${ }^{\mathrm{a}, \mathrm{b}, *}$, George Polizos ${ }^{\mathrm{a}, \mathrm{b}}$, Jin-Young Huh ${ }^{\mathrm{a}, \mathrm{c}}$, \\ Amos Ophir ${ }^{\mathrm{d}}$, Ponusa Songtipya ${ }^{\mathrm{a}, \mathrm{e}}$ and Maria del Mar Jimenez-Gasco ${ }^{\mathrm{e}}$ \\ ${ }^{a}$ Department of Materials Science and Engineering, Pennsylvania State University, \\ University Park, PA 16802, USA \\ ${ }^{\mathrm{b}}$ Polymer Nanostructures Lab - Center for the Study of Polymeric Systems (CSPS), \\ Pennsylvania State University, University Park, PA 16802, USA \\ ${ }^{c}$ Present Address: Samsung, Cheil Industries Inc, Chemical R\&D Center, \\ Uiwang-Si, Gyeonggi-Do 437-711, Korea \\ ${ }^{d}$ Israel Plastics and Rubber Center (IPRC), Ramat-Gan 52526, Israel \\ ${ }^{\mathrm{e}}$ Department of Plant Pathology, Pennsylvania State University, University Park, PA 16802, USA
}

\begin{abstract}
The heat sealing behavior of novel polyethylene-based nanocomposite films was investigated, as they relate to flexible packaging of fresh-cut vegetables, processed foods and biomedical devices. Appropriately designed sealant nanocomposites, which include dispersed montmorillonite nanofillers and ethyl vinyl acetate copolymer, produce a hermetic but peelable heat seal across a broad, $30-40^{\circ} \mathrm{C}$, range of heat sealing temperatures, outperforming optimized commercial polyethylene-based sealants that achieve peelable seals in a much narrower heat sealing temperature range, of less than $15^{\circ} \mathrm{C}$. Appropriate nanocomposite design leads to a general easy-open/peelable character of heat seals, which is: (a) independent of sealing conditions and apparatus - ranging from long dwell times at very high sealing pressures to very short heat impulses at very low sealing pressures; (b) markedly independent of the opposite side of the heat seal - for example, when sealed on itself, on unfilled sealant, or on high density polyethylene; and (c) rather insensitive to formulation variations of the sealant - for example, variations of the polyethylene of the ethyl vinyl acetate type and concentration, and of nanofiller loading. Insights from observations of the fracture seal surfaces by infrared spectroscopy and electron microscopy reveal that the underlying mechanism of this behavior is related to a synergistic effect of the ethyl vinyl acetate copolymer and the montmorillonite clay nanofiller, which introduces weak interfaces in the nanocomposite that lead to cohesive failure of the sealant.
\end{abstract}

(C) Koninklijke Brill NV, Leiden, 2009

\footnotetext{
* To whom correspondence should be addressed: Tel.: (814) 863-2980; Fax: (814) 865-2917; e-mail: manias@psu.edu
} 


\section{Keywords}

Polyethylene heat-sealants, peelable seals, polymer nanocomposites, montmorillonite clay, PE/clay nanocomposites

\section{Introduction}

Polymer/inorganic nanocomposites, in general, and polymer/layered-silicate nanocomposites, in particular, have drawn considerable attention from researchers around the world in recent years [1-4], as they provide a new approach to polymerbased materials that can substantially expand the performance window of plastics and of conventional composites, i.e., composites based on macroscopic/micrometer fillers. Appropriately modified layered-silicates and clays are probably the most widely used nanofillers for polymer/inorganic nanocomposites, due to a combination of low price and ease of dispersion in a wide variety of polymers [1-17], but also because they provide ample opportunities for tailoring, so as to achieve specific materials properties or to address specific application needs. An example that illustrates this last statement comes from recent work on polymer-based adhesive materials [5] - which is also the focus of the present study. In that work, layered-silicate montmorillonite fillers were modified with reactive organic surfactants that simultaneously allowed for dispersion and for chemical bonding with the polyurethane adhesive; this approach yielded nanocomposite adhesives with markedly improved shear and peel strengths, and with increased apparent glass transition temperature [5].

In a first approach, performance improvements can be achieved by simply exploiting the unique features of nanofillers, such as ultra-high surface-to-mass ratios and, in some cases, high aspect ratios and low percolation thresholds. These filler features can give rise to concurrent property enhancements, oftentimes quite substantial in magnitude, in thermomechanical properties, gas and liquid permeabilities, and in thermal stability, typically at very low nanofiller loadings (less than $10 \mathrm{wt} \%$ ) and thus with no loss of the polymer's lightweight character and with no substantial changes in processing conditions. In this form, nanocomposites — probably better described as 'nanofilled polymer composites' [6] — have already found a number of commercial applications. In a more creative approach, nanofillers can also be employed to introduce new functionalities in the composites, i.e., behaviors that are absent in the polymer matrix, effectively changing the nature of the polymer, and resulting in 'genuine nanocomposites', or better described as 'hybrids' or 'molecular composites' [6]. Examples of such new functionalities in nanocomposites include: flame retardancy in most matrices (which originates from a filler stabilized carbonaceous surface char upon exposure to fire [7-11]), substantial increase in heat deflection temperature in polyamides and in poly(vinyl alcohol) (which originates from a new crystal structure promoted by silicate fillers [12-16]), accelerated biodegradability (which originates from catalytic activity of the nanofillers [17-20]), etc. 
Polyethylene (PE) has a large market share in the plastics packaging market, as it is widely used in food, medical and cosmetic products, and also as a sealant with peelable or weld (fused) seals [21-26]. However, in contrast with polar and/or thermosetting polymers, non-polar polymers — such as polyolefins — still present a challenge in preparing well-defined melt-processable nanocomposites with layeredsilicates $[27,28]$; they typically require a two-step processing via dilution of a masterbatch, i.e., a concentrate of a layered-silicate or clay predispersed in a functionalized form of the same polyolefin. For example, direct melt blending of polyethylene (PE) with organically modified clays (organoclays) typically results in microcomposites [27-29], whereas functionalized-PE/layered-silicate masterbatches can facilitate reproducible PE nanocomposite structures [29], even at a large (industrial) scale. In such masterbatch approaches, organoclay is first dispersed at high concentration in a functionalized matrix, for example, maleic anhydride containing polyethylene, and is subsequently diluted/melt-processed with the desired neat polymer, in this example unmodified polyethylene, to obtain the desired nanoscale dispersion.

Given the extensive use of polyethylene sealants worldwide, and the possible enhanced performance of polyethylene/clay nanocomposite films (which combine high gas barrier, optical transparency and improved thermomechanical properties [29-35]) it is very timely to study and tailor the heat-sealing performance of PE/clay nanocomposites, if their use in flexible packaging is to be proliferated. In general, fused PE seals are well established and are straightforward to realize and to manufacture. On the contrary, peelable PE seals necessitate further engineering of the sealant polymer - such as phase-separated PE blends with polybutylene (PB), ionomers, methyl-acrylic acid copolymers, and/or ethyl vinyl acetate (EVA) copolymers [36]. Such blends result in an apparent reduction in area of bonding under heat sealing, and thus to a reduced seal strength. This approach can become rather tedious, since it requires good control of the blend compositions, of the polymer molecular weights and their distributions, and precise control of the sealing conditions (such as sealing temperature and dwell time) and, in addition, these copolymer additives render the sealants sensitive to storage conditions and aging (both for the unsealed films and the packaged products). Given the ability to independently control thermomechanical properties in nanocomposites, one could envision nanocomposite formulations that result in peelable PE-based sealants through a similar approach as with the PE sealant blends, e.g., through incorporation of immiscible polymer/clay domains in a PE sealant. Alternatively, one could design nanocomposites with appropriate nanofiller/polymer interfacial strengths, which would determine the crack initiation and propagation, i.e., determine the failure modes in the final seal, and thus would allow for tailoring the peelability of the heat-seals. This latter approach is the focus of this study.

Specifically, in this paper, we report the design, realization and characterization of polyethylene-based nanocomposite sealant films, reinforced by montmorillonite organoclays. The particular focus is on producing nanocomposite films that can 
form hermetic but peelable heat-seals, and can do so over a broad range of sealing temperatures, times, and pressures, regardless of the counterpart seal surface or the package substrate, and also have improved mechanical properties and can accommodate any additives necessary for end-use. This desired property-set was achieved through a synergistic effect of high performance PE/montmorillonite nanocomposites, and the peelable heat-sealing behavior was introduced via introduction of an ethyl vinyl acetate (EVA) copolymer/organo-montmorillonite weak interface. The seal behavior of these polyethylene-based nanocomposite films was confirmed over a broad range of sealing conditions, and the relevant mechanism is presented.

\section{Experimental}

\subsection{Materials}

Commercial grade polymers and commercial fillers were used throughout this study. The polyethylene used, a commercial grade Integral ${ }^{\mathrm{TM}}$ polyolefin adhesive by Dow, is in fact an 80/20 blend of linear low density polyethylene/low density polyethylene (80/20 LLDPE/LDPE) and will be referred hereafter as PE. Where ethyl vinyl acetate was introduced, it was done by addition of a LDPE copolymer with $18 \%$ vinyl acetate content, a commercial grade Escorene ${ }^{\mathrm{TM}}$ copolymer by ExxonMobil, referred hereafter simply as EVA. As detailed before [21], the amount of EVA-copolymer added can range between $30 \%$ to $80 \%$ with respect to the PE sealant, with no change in the sealing behavior reported in this work (see also Section 3.2.3); although other properties of the sealant film — such as mechanical, haze and surface roughness - will vary with the amount of EVA-copolymer [21], but these properties are of no interest here. The layered-silicates were commercial organo-montmorillonites, with a cation exchange capacity (CEC) of about $1.0 \mathrm{meq} / \mathrm{g}$ and were organically modified with dimethyl-dioctadecyl-ammonium surfactants, purchased from Nanocor, Arlington Heights, IL. These oganoclays were dispersed at $25 \mathrm{wt} \%$ inorganic loading with a twin-screw extruder in two maleic anhydride (MAH) functionalized polyethylenes (a $0.23 \mathrm{wt} \% \mathrm{MAH}-$ graftLDPE, $M_{\mathrm{w}}=62000$ and $M_{\mathrm{w}} / M_{\mathrm{n}}=6$ and a $0.26 \mathrm{wt} \%$ MAH-graft-LLDPE, $M_{\mathrm{w}}=67000 \mathrm{~g} / \mathrm{mol}$ and $\left.M_{\mathrm{w}} / M_{\mathrm{n}}=6.1\right)$ to mimic, respectively, commercially available LDPE and LLDPE masterbatches [37]. Nanocomposites were subsequently formed by dilution of these concentrates in the PE sealant using a single-screw extruder (barrel diameter $d=30 \mathrm{~mm}$; barrel length/diameter ratio $L / d=36: 1$; with a heating profile of $145,145,185,185,185,185$ and $185^{\circ} \mathrm{C}$ from feed to nozzle; operated at a rate of $\sim 12.7 \mathrm{~kg} / \mathrm{h}$ ). Blown films were produced on an industrial line (Pliant Corporation, Chippewa Falls, WI) with identical processing parameters and equipment as current commercial food packaging films, but with varied compositions and film thicknesses, including: neat (unfilled) polymers, blends, and nanocomposites (monolayers), and sealant nanocomposites coextruded on a high density polyethylene (HDPE) substrate (multilayer blown films). The characteristics of the blown films are summarized in Table 1. PE is a monolayer 
Table 1.

Tensile properties of selected sealant materials and of their respective blown thin films

\begin{tabular}{lllllll}
\hline $\begin{array}{l}\text { Film } \\
\text { designation }\end{array}$ & \multicolumn{2}{l}{ Materials properties } & & \multicolumn{2}{l}{ Thin film properties } \\
\cline { 2 - 3 } & $\begin{array}{l}\text { Yield } \\
\text { strength } \\
(\mathrm{MPa})\end{array}$ & $\begin{array}{l}\text { Strength } \\
\text { at break } \\
(\mathrm{MPa})\end{array}$ & & $\begin{array}{l}\text { Film } \\
\text { thickness } \\
(\mathrm{mm})\end{array}$ & $\begin{array}{l}\text { Yield strength } \\
\text { of a 25.4-mm- } \\
\text { wide strip } \\
(\mathrm{N} / \mathrm{cm})\end{array}$ & $\begin{array}{l}\text { Strength at break } \\
\text { of a 25.4-mm- } \\
\text { wide strip } \\
\text { (N/cm) }\end{array}$ \\
\hline PE & $12.9 \pm 0.3$ & $29.1 \pm 0.5$ & $0.097 \pm 0.004$ & $12.5 \pm 0.1$ & $28.2 \pm 0.4$ \\
PE/EVA & $\begin{array}{l}\text { breaks prior } \\
\text { to yielding }\end{array}$ & $30.6 \pm 1.8$ & $0.058 \pm 0.003$ & - & $17.2 \pm 1.9$ \\
PE/clay & $16.5 \pm 0.2$ & $29.5 \pm 1.4$ & $0.061 \pm 0.004$ & $10.2 \pm 0.1$ & $18.1 \pm 0.8$ \\
PE/EVA/clay & $26.2 \pm 1.0$ & $28.8 \pm 1.4$ & $0.062 \pm 0.006$ & $16.1 \pm 0.6$ & $17.7 \pm 0.8$ \\
\hline
\end{tabular}

of the sealant (LDPE/LLDPE blend); PE/EVA is a multilayer of $20 \mu \mathrm{m}$ sealant (LDPE/LLDPE with $30 \%$ EVA-copolymer) on a HDPE substrate; PE/clay is a monolayer of sealant/clay nanocomposite (LDPE/LLDPE with $6 \mathrm{wt} \%$ of organomontmorillonite, via a MAH-graft-LLDPE masterbatch); and PE/EVA/clay is a multilayer of $20 \mu \mathrm{m}$ sealant (LDPE/LLDPE with 30\% EVA-copolymer, reinforced by $6 \mathrm{wt} \%$ of organo-montmorillonite, via MAH-graft-LLDPE masterbatch) on a HDPE substrate. Where necessary, additional commercial-grade packaging films donated by Kraft Global Foods, Pliant Corp., and Alcan Packaging were also tested as received.

\subsection{Heat Sealing Conditions}

Three different sealing apparatus, offering significantly different sealing conditions, were employed to heat seal films in this study:

(a) High pressure and long dwell time heat seals were done on a Carver laboratory hot-press, operated with only the upper plate heated at a constant temperature $\left(110-140^{\circ} \mathrm{C}\right)$ and pressed on the two-film specimens at $6.89 \mathrm{MPa}(1000 \mathrm{psi})$ for $8 \mathrm{~s}$. The specimens, two 25.4 by $120 \mathrm{~mm}$ strips, were mounted on the lower plate at ambient temperature and covered by a Teflon film. The high sealing pressure and long dwell time ensure equilibration of the temperature at the sealing surface (interface) independent of film thickness and composition [21, 23] (see Note 2).

(b) An ASTM conforming Sentinel Heat Sealer (Sencorp Inc., Hyannis, MA) was also used, operated with two-side heated seal bars, at constant temperature, at $0.276 \mathrm{MPa}(40 \mathrm{psi})$ pressure and $0.5 \mathrm{~s}$ dwell time, as per the ASTM standards [38] (see Note 2).

(c) An Impulse Sealer (KF-300H model, GHL Packaging Inc., San Dimas, CA) was used for short dwell times and low pressures. This benchtop impulse sealer 
has a 2-mm-wide heated flat band bottom side, and a rubber jaw on the top; it operates at a constant impulse power of $146 \mathrm{~W}$ with the sealing/heating time varied from 0.2 to $1.3 \mathrm{~s}$, depending on the impulse dial setting, varying the temperature accordingly. For this last setup, films were cut into 50 by $120 \mathrm{~mm}$ strips, and 5 parallel sealed lines (2-mm-wide each, separated by 2 -mm-wide unsealed spacing) were defined along the strips, resulting in a serrated geometry seal with $10 \mathrm{~mm}$ total seal width.

\subsection{Seal Strength}

All peel tests were performed according to ASTM F88-06 standard on an Instron 5866 tensile tester machine, operated with pneumatic grips, separating the two specimen legs at $180^{\circ}$, leaving the sealed area at $90^{\circ}$ with each leg (unsupported protocol [38]), starting from an initial distance between the two grips of about $10 \mathrm{~mm}$, and using a constant separation speed of $200 \mathrm{~mm} / \mathrm{min}$. Complete stress-strain curves were recorded for 5 to 10 independent specimens per seal, and were subsequently used to quantify the maximum and average seal strength per width of seal; the average seal strength is reported for peelable seals, while the maximum seal strength is reported for weld (fused) seals. The seal failure mode was also determined by visual observation of the broken specimens, according to ASTM F88-06. Where it was necessary to know the tensile properties of the materials and of the blown films (especially in the case of multilayer blown films), the same tensile tester was employed on bulk specimens. Type V dogbone specimens (ASTM D638-03) at $3.2 \mathrm{~mm}$ thickness were used for the bulk materials properties, whereas Type I dogbone specimens (ASTM D638-03) at the blown-film thickness were used for the film specimens. Tensile measurements were done according to ASTM D638-03 for the bulk specimens and ASTM D882-02 for the blown films.

\subsection{Nanocomposite Morphology}

For the nanocomposite films, X-ray diffraction (XRD) was used to quantify any intercalated layered-silicate structures, and was carried out on a Rigaku Geiger-flex powder diffractometer with a Dmax-B controller and a vertical goniometer. The instrument used radiation from a copper target tube $\left(\mathrm{Cu} \mathrm{K}_{\alpha}\right.$ radiation at $\left.\lambda=1.542 \AA\right)$ and diffraction data were typically collected for $2 \theta$ from $1^{\circ}$ to $10^{\circ}$. In addition, bright field Transmission Electron Microscopy (TEM) images were obtained with a JEOL-1200EXII microscope operated at $120 \mathrm{kV}$. Ultra-thin sections from the specimens were prepared at about $-100^{\circ} \mathrm{C}$ with a cryo-microtome (Diatome, Biel, Switzerland) equipped with a diamond knife, and were transferred dry to 200-mesh carbon-coated copper TEM grids. No staining of sections was required, since there exists sufficient contrast between the inorganic nanofillers and the polymer matrix [39]. Finally, the various nanocomposites were also studied by differential scanning calorimetry (DSC) and were compared against the respective unfilled polymers. All DSC measurements were carried out in a Modulated DSC (Q100 
from TA Instruments) at heating and cooling ramp rates of $10^{\circ} \mathrm{C} / \mathrm{min}$, operated in normal or modulated mode as needed, and always under a nitrogen/helium flow.

\subsection{Characterization of the Fracture Surfaces}

The surfaces of the films after the peel tests were directly observed by environmental scanning electron microscopy (ESEM), which was performed in an FEI Quanta 200 environmental scanning electron microscope, operated under vacuum. No metal coating was applied to the fracture surface. The microscope is equipped with an Oxford Inca energy-dispersive X-ray system. Energy-dispersive X-ray spectra (EDS) were collected for qualitative elemental analysis of the surfaces. For more sensitive chemical analysis, attenuated total reflection Fourier transform infrared (ATR-FT-IR) spectra were collected from the fractured seal surfaces, i.e., the seal surfaces after the peel test, and were compared against the original (unsealed) respective films. All ATR-FT-IR spectra were recorded on a Digilab Scimitar 1000 (Digilab Global, Randolph, MA), at $2 \mathrm{~cm}^{-1}$ resolution, under ambient atmosphere.

\section{Results and Discussion}

\subsection{Characterization of the Sealant Nanocomposites}

\subsubsection{Morphology and Dispersion}

The sealant films containing montmorillonite (mmt) nanofillers were made through a two-step masterbatch process, as described in the Experimental Section. Masterbatch dilution is the best-established approach to prepare polyolefin/clay nanocomposites [27-29, 37, 41], wherein dialkyl-ammonium montmorillonite was dispersed in maleic anhydride functionalized polyethylene (either LDPE or LLDPE). The MAH-graft-PE masterbatches (at $25 \mathrm{wt} \%$ of inorganic clay, or equivalently $40 \mathrm{wt} \%$ of organoclay) were diluted in the sealant matrices by melt blending in a singlescrew extruder, to the desired final filler content. Powder X-ray diffraction (XRD) can detect the basal d-spacing of montmorillonite (for example, for dry mmt $\mathrm{d}_{001} \sim 1 \mathrm{~nm}$, or $2 \theta \sim 9^{\circ}$ ) and record its shift to lower $2 \theta$, larger $\mathrm{d}_{001}$ spacings, as montmorillonite expands to accommodate the organic modification and any intercalated polymers (for example, for both masterbatches $\mathrm{d}_{001} \sim 2.75 \mathrm{~nm}$, or $2 \theta \sim 3.20^{\circ}$, Fig. 1). Upon diluting with the sealant, the $\mathrm{d}_{001}$-spacing does not change markedly, there is only a slight increase, but the diffraction peak broadens and its intensity decreases, strongly indicating further dispersion of the intercalated fillers in the nanocomposite sealant. With addition of the EVA-copolymer in the sealant there is a marked increase in the $\mathrm{d}_{001}$-spacing (to about $3.74 \mathrm{~nm}$, or $2 \theta \sim 2.36^{\circ}$, Fig. 1), indicating even further swelling of the intercalated fillers aided by the polar EVA-copolymer (see Note 1) [40]. This $1 \mathrm{~nm}$ increase in $\mathrm{d}_{001}$-spacing with EVA is in good agreement with previous work [41], where just $1 \mathrm{wt} \%$ of EVA was sufficient to expand the $\mathrm{PE} /$ montmorillonite $\mathrm{d}_{001}$-spacing. The dispersion of the nanofillers in the nanocomposite sealants (PE and PE/EVA) can also be directly viewed by TEM of the blown films, Fig. 2, which shows a very good dispersion for the nanofillers, 


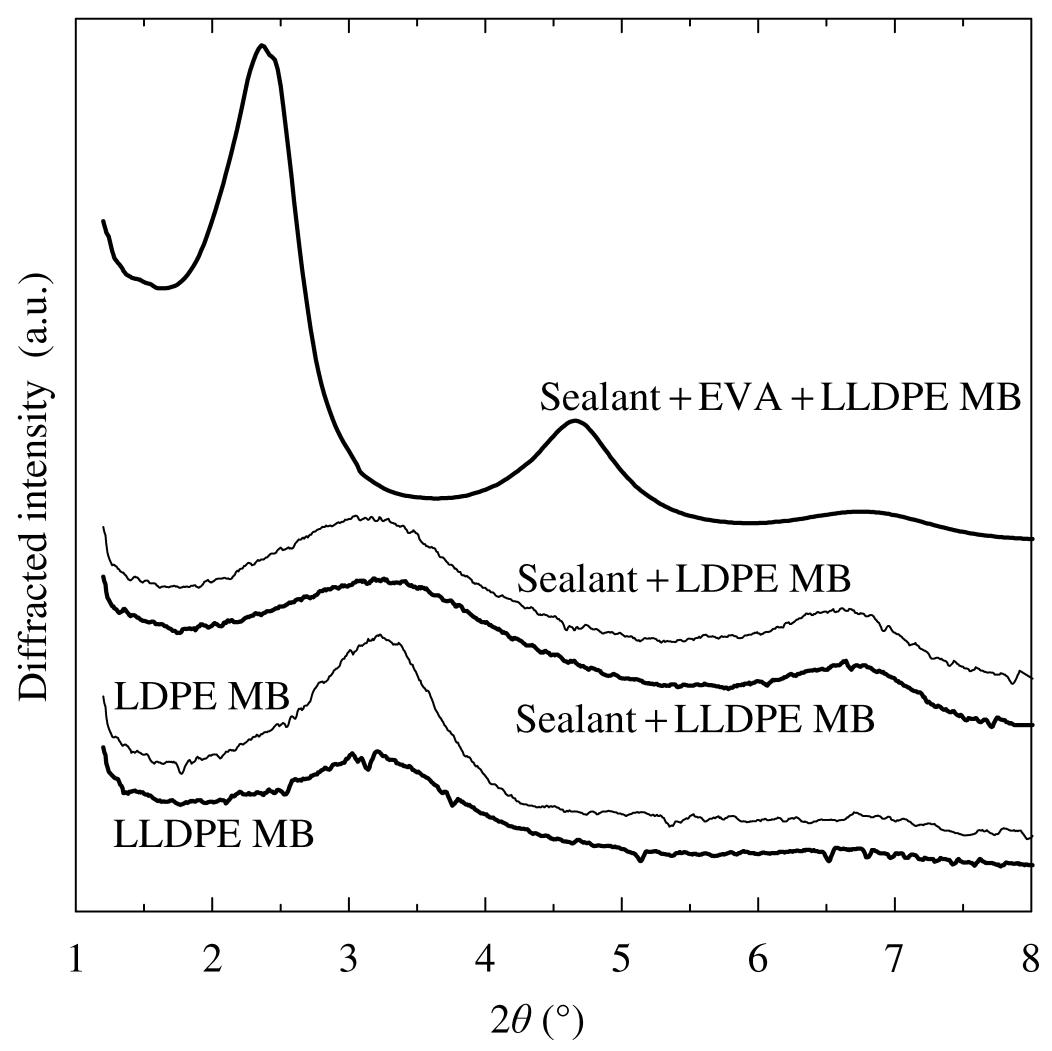

Figure 1. XRD patterns of the montmorillonite $\mathrm{d}_{001}$ basal spacing for the two PE masterbatches (MB) based on MAH-graft-LDPE and MAH-graft-LLDPE, for the two respective PE-sealant nanocomposites (from the dilution of each masterbatch by the LLDPE/LDPE sealant), and for the nanocomposite made from the LLDPE masterbatch diluted by sealant and EVA-copolymer.

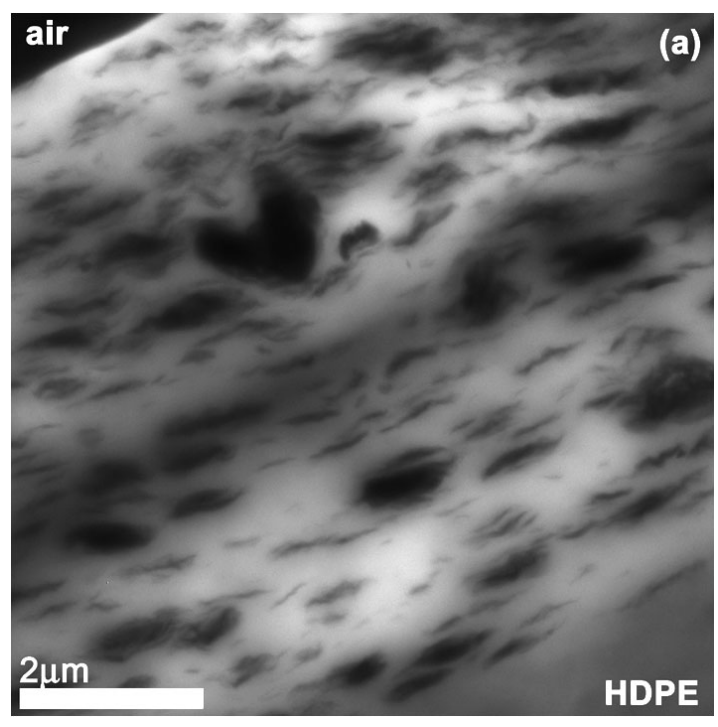

(a)

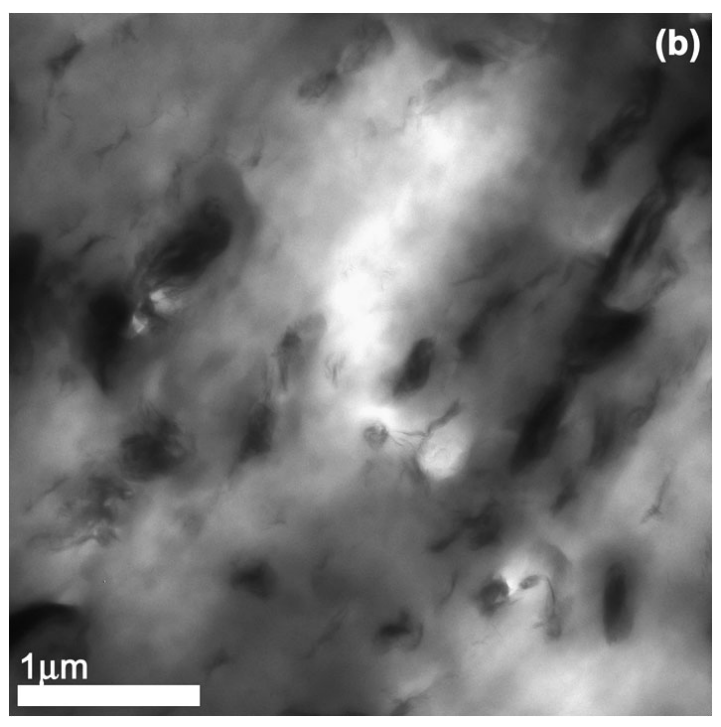

(b)

Figure 2. TEM images of the HDPE-supported PE/EVA/montmorillonite nanocomposite sealant, via the MAH-graft-LLDPE masterbatch. (a) The whole thickness of the nanocomposite sealant film on HDPE. (b) A higher magnification of the same region, illustrating the nanofiller dispersion. 
comparable with the dispersions obtained when using optimized (LDPE/mmt or LLDPE/mmt) commercial masterbatches [37].

\subsubsection{Thermal Properties}

Given the composition of our nanocomposite sealant films, nanofilled blends of two to four PE-based polymers with varying degrees of crystallinity and varying melting temperatures, it is not obvious how the crystallization behavior will be affected by the blend composition and/or by the dispersion of the montmorillonites. Thus, in order to assess the proper sealing temperatures, the melting points of the sealant and the sealant nanocomposites were characterized by DSC, as were the multilayer blown-films of the sealants supported on a HDPE substrate, Fig. 3. The DSC heating traces of the PE and PE/mmt nanocomposites (Fig. 3a) show the characteristic LLDPE/LDPE blend dual melting point, at about 121 and $110^{\circ} \mathrm{C}$. The incorporation of the nanofiller (which is done through the addition of a masterbatch and thus introduces a third polyethylene, the MAH-graft-LDPE, in Fig. 3a) does not alter the melting beyond the expected reduction in the enthalpy of melting. Also, further processing of these sealants, both nanocomposite and unfilled, into blown films does not affect their melting behavior, whereas when supported on HDPE substrates the DSC melting trace is overwhelmed by the HDPE melting endotherm at around $130^{\circ} \mathrm{C}$ and the LLDPE/LDPE melting peaks are barely noticeable at about the same temperature as the sealant systems (Fig. 3b). According to these DSC melting traces, heat sealing temperatures between $90^{\circ} \mathrm{C}$ and $150^{\circ} \mathrm{C}$ should be effective for the sealants used [23].

\subsubsection{Mechanical Properties}

Given the compliant character of the PE-based sealants and the relatively good dispersion of the montmorillonites achieved, the sealant nanocomposites of this work exhibit a substantial improvement in the mechanical properties compared to the respective unfilled sealants. Table 1 summarizes some of the changes in the mechanical properties for the sealant blown films used for the heat sealing and peel tests. The detailed mechanical properties of the sealant nanocomposites are shown elsewhere [42]. The general trends (in both the machine and the transverse directions of the blown film) included: a substantial increase in tensile Young's modulus ( 80 to $160 \%$ increase for 2 to $5 \mathrm{wt} \% \mathrm{mmt}$ ), no marked change in the tensile strength (a slight 10\% improvement in machine direction and a 10\% decrease in the transverse direction), no marked change in the yield stress and strain, and a small decrease in the tensile strain at break (from 550\% to $460 \%$ in the machine direction, whereas in the transverse direction remained unchanged at $650 \pm 50 \%$ ). These trends strongly reflect the proper choice of the functionalized PE in the montmorillonite masterbatch, namely a functional MAH-graft-LLDPE with a molecular weight and density commensurate with the LDPE/LLDPE sealant blend, rather than a straightforward effect of the clay dispersion [29]. 


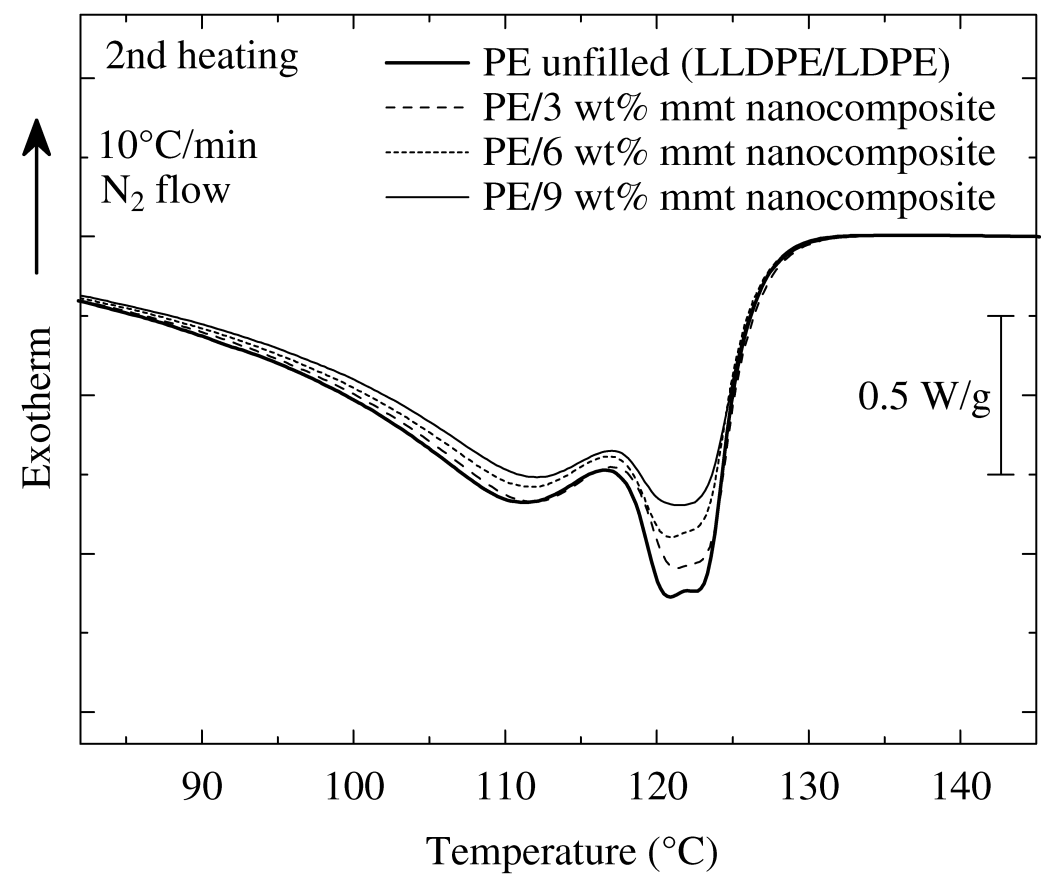

(a)

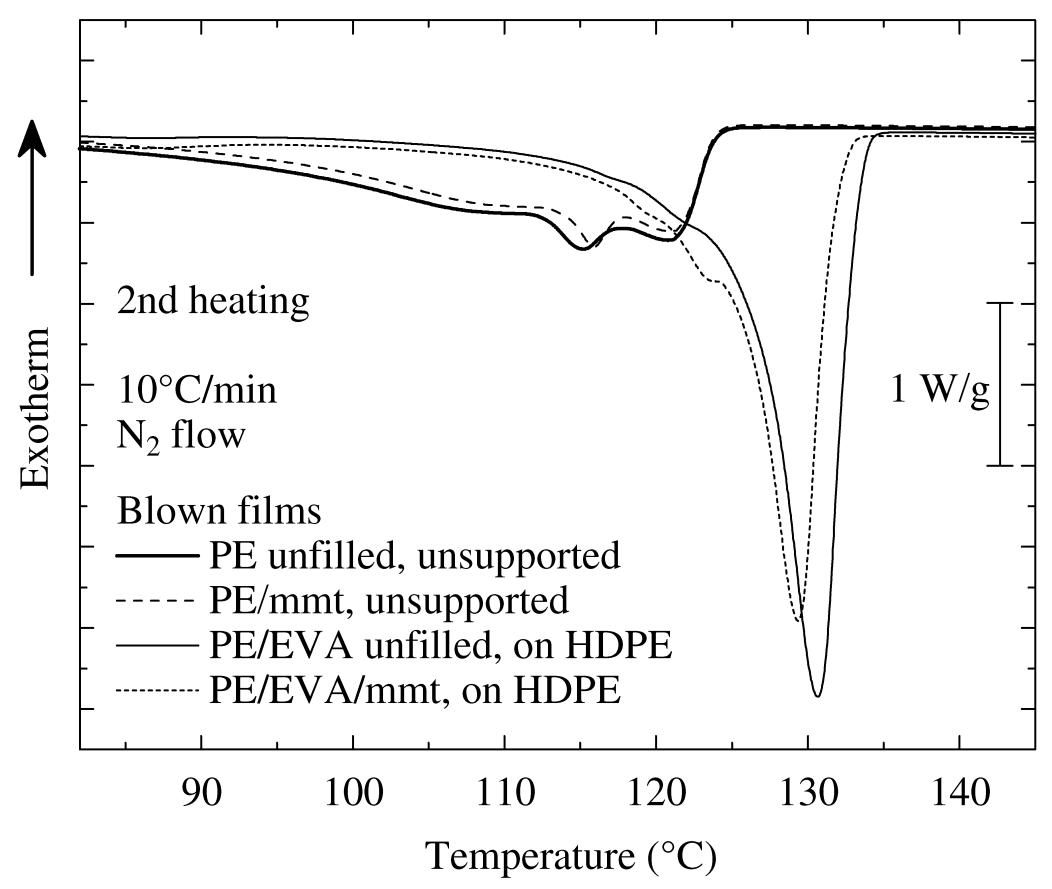

(b)

Figure 3. Second heating DSC traces of: (a) bulk sealant materials (PE and PE/mmt nanocomposites at various filler loadings); (b) various blown films (PE and PE/mmt are monolayer blown films; PE/EVA and $\mathrm{PE} / \mathrm{EVA} / \mathrm{mmt}$ are multilayer blown films with EVA-containing sealants supported on HDPE).

\subsection{Heat Seal Strength and Peel Behavior}

Three different sealing approaches, offering significantly different sealing conditions, were employed to heat seal films in this study, so as to investigate sealing 
behavior both at equilibrium as well as under application-related conditions [43]. Specifically, flat 25.4-mm-wide seals were first done under high pressure and long dwell times (at $6.89 \mathrm{MPa}$, i.e., $1000 \mathrm{psi}$, for $8 \mathrm{~s}$ ). These conditions ensure temperature equilibration at the sealing surface (interface) for all films studied here (see Note 2), independent of their thickness and composition [21-23]. Additionally, to better mimic the short sealing times of practical applications, similar 25.4-mmwide flat seals were prepared per the ASTM protocol [38] at $0.2758 \mathrm{MPa}$ (40 psi) and $0.5 \mathrm{~s}$ dwell time, conditions that may marginally approach thermal equilibration of the sealing interface [23]. Finally, serrated $10-\mathrm{mm}$-wide seals (5 parallel 2-mm-wide sealed lines) were done in a benchtop impulse sealer, operated at a constant impulse power of $146 \mathrm{~W}$ with heating times varied from 0.2 to $1.3 \mathrm{~s}$; for this setup and for the shortest dwell times, there would definitely be variations in the sealing temperature and behavior, since the heat transfer will vary between systems depending on film thickness and composition. However, the sealing behavior probed in this manner would better relate to most of the common practical applications [43].

\subsubsection{High Pressure and Long Dwell Time Heat-Seals}

For polymeric heat sealants the seal strength and quality are controlled primarily by three factors: sealing temperature, dwell time, and applied pressure, with the first two parameters having the predominant effect on the seal strength [21]. For a semicrystalline polymer, strong heat-seals typically form only when the polymer melts $[23,43]$, showing two characteristic temperatures for a polymer seal: (a) the 'seal initiation temperature', the lowest temperature at which a measurable seal strength can be achieved and (b) the 'plateau initiation temperature', the lowest temperature at which the maximum seal strength is achieved; for example, for the PE sealant used in this study the initiation temperature is slightly above $120^{\circ} \mathrm{C}$ and the plateau temperature is about $125^{\circ} \mathrm{C}$ (Fig. 4). The temperature gap between seal initiation and plateau initiation temperatures is called 'transition zone'. Given the wide industrial usage of $\mathrm{PE}$ as a sealant in flexible packaging applications, the heat sealing behavior of polyethylene films has been well studied (e.g., [21-23] and references therein). For PE-based sealants, the transition temperature zone is very narrow (in this case less than $5^{\circ} \mathrm{C}$, Fig. 4) which dictates that for most sealing practices one can achieve either a fused seal or no seal at all, as the temperature is varied. Equivalently, this also means that if one wishes to achieve a peelable hermetic heat seal, one needs to precisely control the sealer temperature so that the temperature at the sealing interface is within the transition zone, yielding a seal strength within the peelable range; here this corresponds to a temperature window of about half a degree slightly above $120^{\circ} \mathrm{C}$ (Fig. 4). This last condition becomes very laborious, and most often impractical for an industrial setting, especially when the sealant film thickness, the substrate characteristics, and the heat sealer condition can vary from day to day and from batch to batch. Alternatively, EVA, PB, or other (co)polymers [23] can be added to better control the heat sealing for PE sealants. Thus, a dependable high-quality heat seal can be made at lower seal initiation temperature and over 


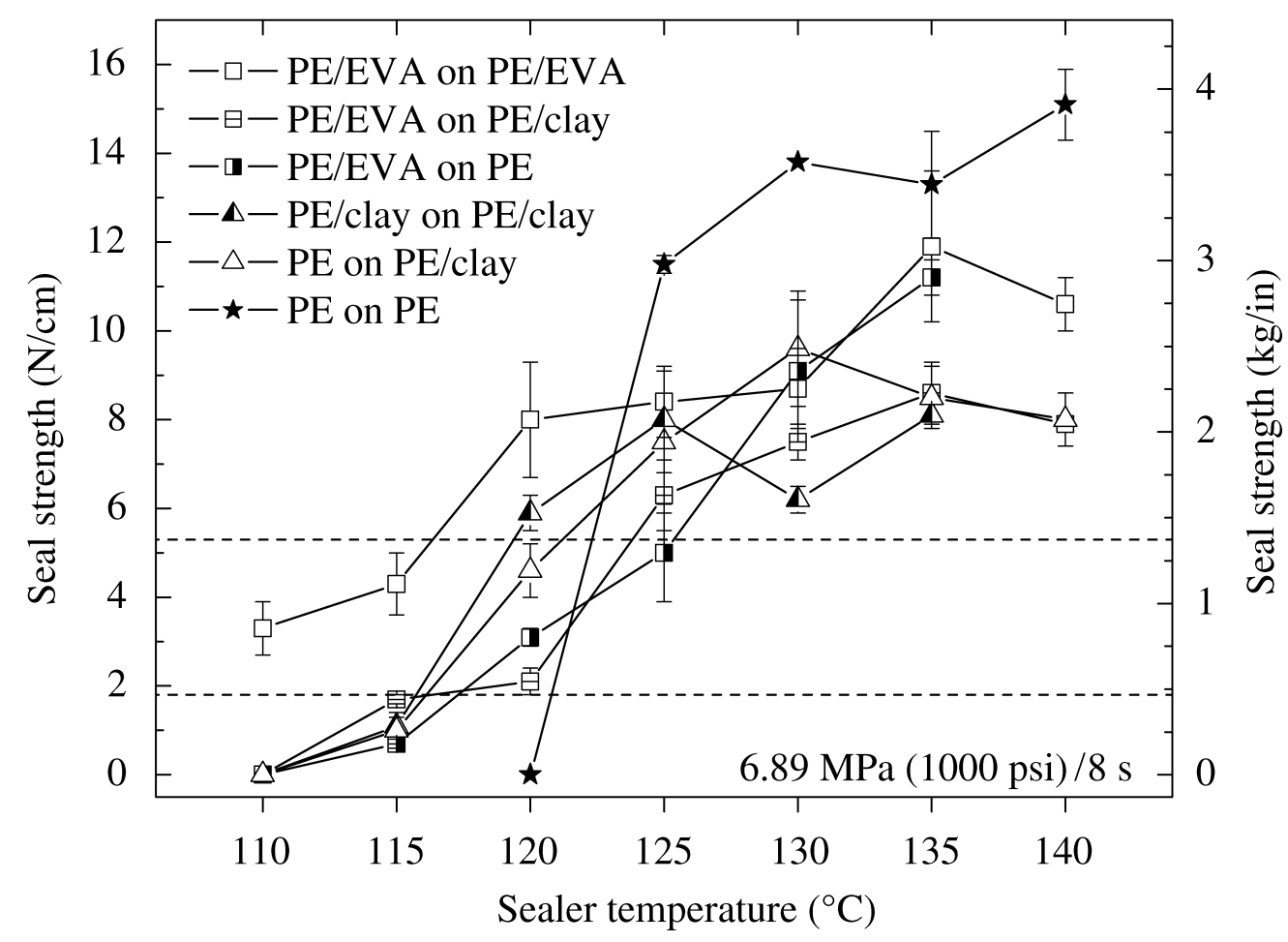

Figure 4. Seal strengths for large pressure and long dwell time (25.4-mm-wide flat seals; $8 \mathrm{~s}$, seal interface temperature equilibrated at the sealer temperature (see Note 2)). The dashed lines indicate the range of peelable seal strengths. [PE: neat LLDPE/LDPE sealant blend. PE/clay: nanocomposite of the same sealant blend (4 wt\% montmorillonite via LLDPE/clay master-batch). PE/EVA: same sealant blend with LDPE-EVA-copolymer.]

a broader range of sealing conditions, while at the same time the seal strength can be altered via the copolymer content. In our case, addition of the EVA-copolymer decreases the seal initiation temperature below $100^{\circ} \mathrm{C}$, reduces the ultimate seal strength by about $30 \%$, and allows for peelable seals for interface temperatures in the range of $110-115^{\circ} \mathrm{C}$ (Fig. 4). Even in this case, the temperature range for obtaining a peelable and hermetic seal still remains too narrow - just $5^{\circ} \mathrm{C}$ wide from an industrial/application viewpoint.

Seal strengths for various systems based on the same PE sealant, with added ethyl vinyl acetate (EVA) copolymer and/or its montmorillonite-reinforced nanocomposites, are also shown in Fig. 4. A seal strength in the range 1.8-5.3 N/cm $(1-2.5 \mathrm{lb} / \mathrm{in})$ allows for convenient (easy-open) opening for typical seal widths in flexible packaging [44]. The neat sealant (PE on PE in Fig. 4) showed a heat seal with very narrow transition zone - there was no seal at or below $120^{\circ} \mathrm{C}$, whereas it becomes fused above $125^{\circ} \mathrm{C}$. For its montmorillonite-filled nanocomposite and its blend with EVA-copolymer added (PE/clay and PE/EVA, respectively, in Fig. 4) the seal initiation temperature is lowered, the transition zone broadens, and the seal strength increases more gradually before reaching the fused seal plateau; however, even for these systems the peelable sealing temperature region is still rather narrow (about $5-10^{\circ} \mathrm{C}$ ). All seals become fused for a temperature higher than $125^{\circ} \mathrm{C}$, or even be- 
Table 2.

'Map of peelability' for various seals, $6.89 \mathrm{MPa}(1000 \mathrm{psi}) / 8 \mathrm{~s}$. The long dwell time ensures that the interface (sealing) temperature is well-equilibrated at the apparatus (sealer) temperature (see Note 2)

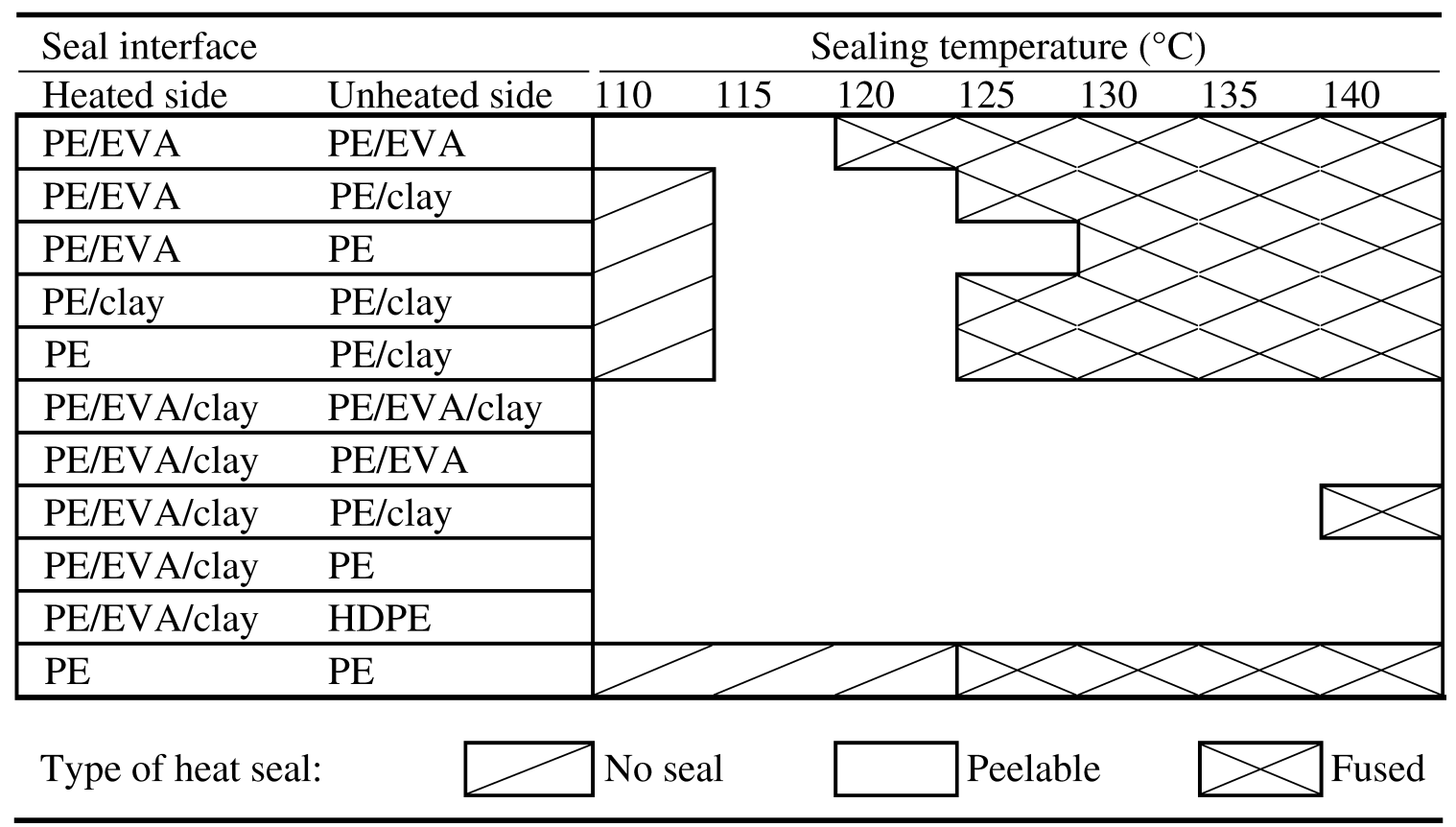

low that for the EVA-containing systems (for example, above $120^{\circ}$ for PE/EVA on PE/EVA). The failure types of various seals are shown in Table 2.

The goal of this work is to produce materials that allow for heat seals with easy opening and, at the same time, afford a reliable hermetic seal, and achieve peelability over a very broad range of sealing temperatures/conditions. This is much more challenging than simply lowering the seal initiation temperature (something that can be done with appropriate additions of a lower melting point polymer, for example, EVA or PB copolymers) and is also more difficult than strengthening the seal (something that can also be done via nanocomposites, where filler/matrix chemical bonds can be introduced by design [5]). One way to achieve peelability with no loss of seal reliability is to design a nanocomposite with a polymer/filler interface that is weak enough for the sealant to fail cohesively prior to reaching the sealant's adhesion strength and, at the same time, is strong enough to afford dispersion and good mechanical properties of the sealant (maintain a robust film and a reliable hermetic seal). This obviously cannot be done by straightforward organomontmorillonite incorporation in PE, since they are immiscible, and it cannot be done by MAH-co-PE/montmorillonite masterbatches, which are well-dispersed in $\mathrm{PE}$ but have sufficiently strong interfacial adhesion - comparable to PE cohesion [45] — that does not afford peelable seals (cf. Fig. 4). However, it can be done by incorporating LDPE-VA-copolymers in the nanocomposite sealant, in such a manner that the EVA-copolymer will segregate to the filler interfaces - due to the favorable EVA/montmorillonite polar interactions (Fig. 1) - and can also provide 


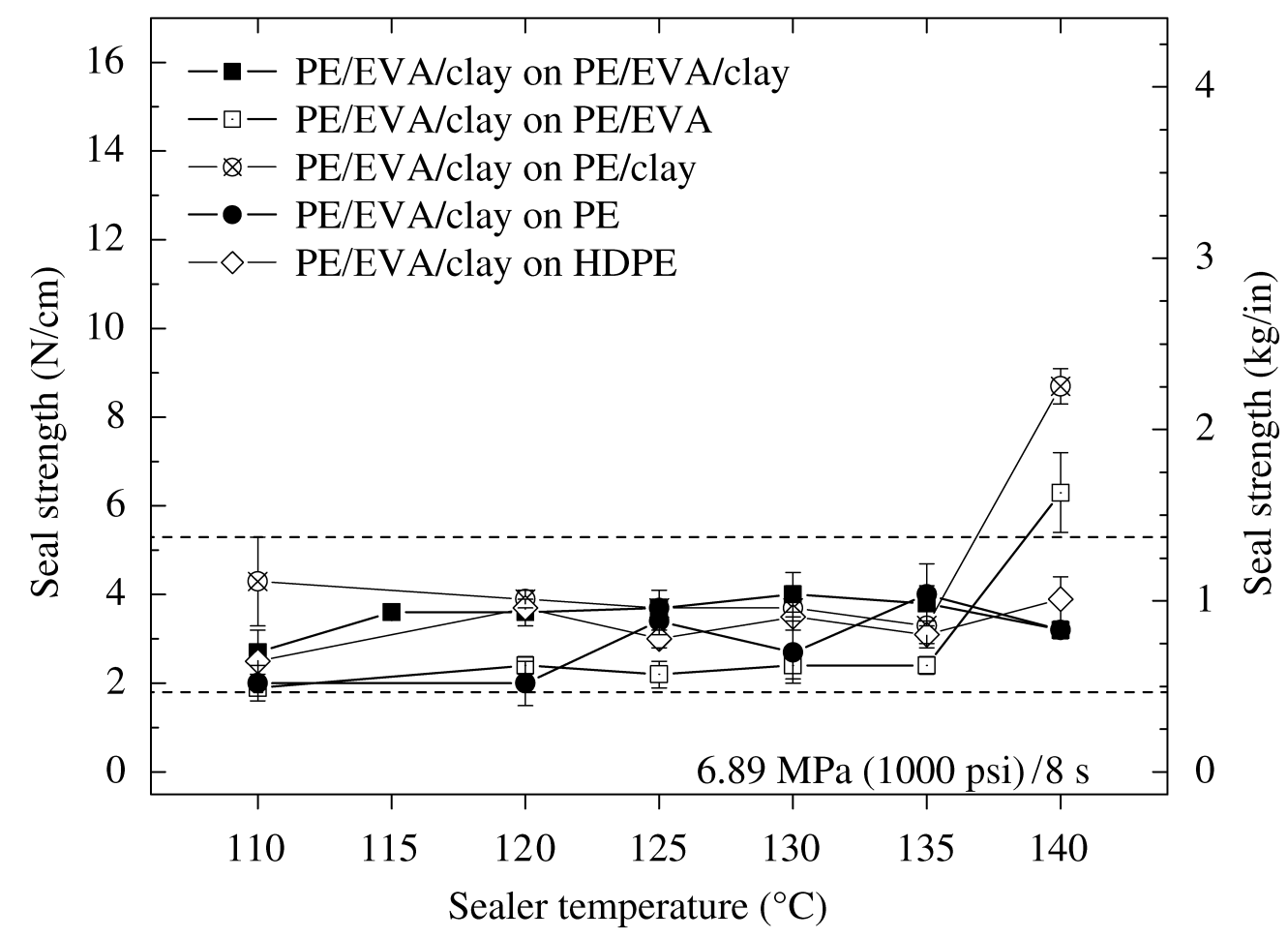

Figure 5. Seal strengths for 25.4-mm-wide flat seals for large pressure and long $(8 \mathrm{~s})$ dwell time (see Note 2). The horizontal dashed lines indicate the range of peelable seal strengths. PE/EVA/clay achieves peelable heat seals over a very broad range of sealing temperatures, independent of the substrate sealed on. [PE/EVA/clay: the PE/EVA sealant film reinforced by organo-montmorillonite, coextruded on a HDPE. All other materials as in Fig. 4.]

low enough interfacial strength to allow for easy open - due to the LDPE branched polymer microstructure of the EVA-copolymer (Fig. 5).

This design of the PE/EVA/clay film sealant leads to significant differences in sealing behavior, compared to the standard PE/EVA sealant and the neat PE sealant (Table 2; or Fig. 4 vs. Fig. 5). When PE/EVA/clay films are sealed on PE/EVA/clay films, hermetic but peelable seals are formed over a very broad range of temperatures, from 110 to $140^{\circ} \mathrm{C}$, with a seal strength of about 3-4 N/cm, and fused seals are formed only above $140^{\circ} \mathrm{C}$ for all systems (Fig. 5). For temperatures higher than $140^{\circ} \mathrm{C}$, and given the high pressure and long dwell time, the HDPE substrate film may also contribute to the seal [23], so results for these temperatures are not reported here. Additionally, when PE/EVA/clay is sealed on other films - such as $\mathrm{PE}, \mathrm{PE} / \mathrm{EVA}, \mathrm{PE} / \mathrm{clay}$ and HDPE - it again leads to the formation of hermetic and peelable seals, for sealing temperatures between $110^{\circ}$ and $135^{\circ} \mathrm{C}$, and with a similar seal strength (2-4 N/cm, Fig. 5). This 'universal' peelable heat sealing behavior, markedly independent of the second surface and with comparable seal strengths, strongly indicates that the peelability originates from the nature of the PE/EVA/clay nanocomposite sealant, as discussed later in this paper.

In many cases, the seal strength, i.e., the maximum force to separate a seal between two films, can be limited by the breaking strength of the films, i.e., the 
maximum tensile force to break the film itself. Also, while testing the thin film specimens for seal strength, the load transmitted by the film to the sealing path may yield the bulk of the film prior to the onset of the peeling process. Both these effects may become relevant for some of the fused seals of this study, as can be seen by comparing the various seal strengths (Figs 4 and 5) with the tensile properties of the respective 25.4-mm-wide films (Table 1). Thus, a material independent quantity is often used to characterize heat seals across various materials and systems, namely, the 'seal index' defined as [24]:

$$
\text { Seal index }=\frac{\text { Seal strength }}{\text { Breaking strength of the film }}
$$

The seal index allows for comparisons of seals between different materials systems, or for seals between different films (e.g., of varied thickness) of the same material. For those seals that are between the same materials, the above definition is straightforward; for those seals that are between two different materials, the above definition is used with the breaking strength of the weaker film. The seal indices that correspond to the data of Figs 4 and 5 are shown in Fig. 6, in a form which is probably more appropriate if one is to compare between all the different materials/films studied here. For the seals between PE, PE/clay and PE/EVA - sealed on themselves or on each other - the seal index is about $0.55 \pm 0.1$, when the sealing temperature is higher than $120^{\circ} \mathrm{C}$, indicating fused seals (Fig. 6). For the seals of $\mathrm{PE} / \mathrm{EVA} /$ clay, the seal index is about $0.17 \pm 0.1 \mathrm{in}$ almost all cases, indicating a peelable seal (Fig. 6). It is noteworthy that the addition of the EVA-copolymer alone, or the formation of the clay nanocomposite alone, does not affect the seal index of the PE (it remains about 0.55); on the contrary, EVA-copolymer and clay together significantly influence the seal index, setting it to about 0.17 (indicating a peelable seal), and they do so over a broad range of sealing temperatures and independent of the material that is sealed on. This last observation strongly suggests a synergistic effect of the EVA-copolymer and the montmorillonite (clay) filler in the PE sealant nanocomposites, as will be demonstrated in detail in the following section.

\subsubsection{Low Pressure and Short Dwell Time Heat-Seals (Impulse Sealer)}

Arguably, the heat sealing conditions used for Figs 4 and 5 are rather extreme, employing high pressures and very long dwell times. Although these conditions guarantee full equilibration of the seal interface temperature and elimination of any kinetic effects from the sealants [21-23], they can raise questions on the reproducibility of the sealing behaviors reported above under typical application conditions of heat-sealing. Thus, another sealing method was also employed, via an impulse thermal sealer, to test the reproducibility of these behaviors under more application-relevant conditions. The obtained seal strengths are shown in Fig. 7. Although the exact sealing time, temperature, or pressure cannot be recorded (due to the nature and design of the impulse sealer), this approach clearly operates at the reverse set of sealing conditions than above, i.e., short dwell times and very 


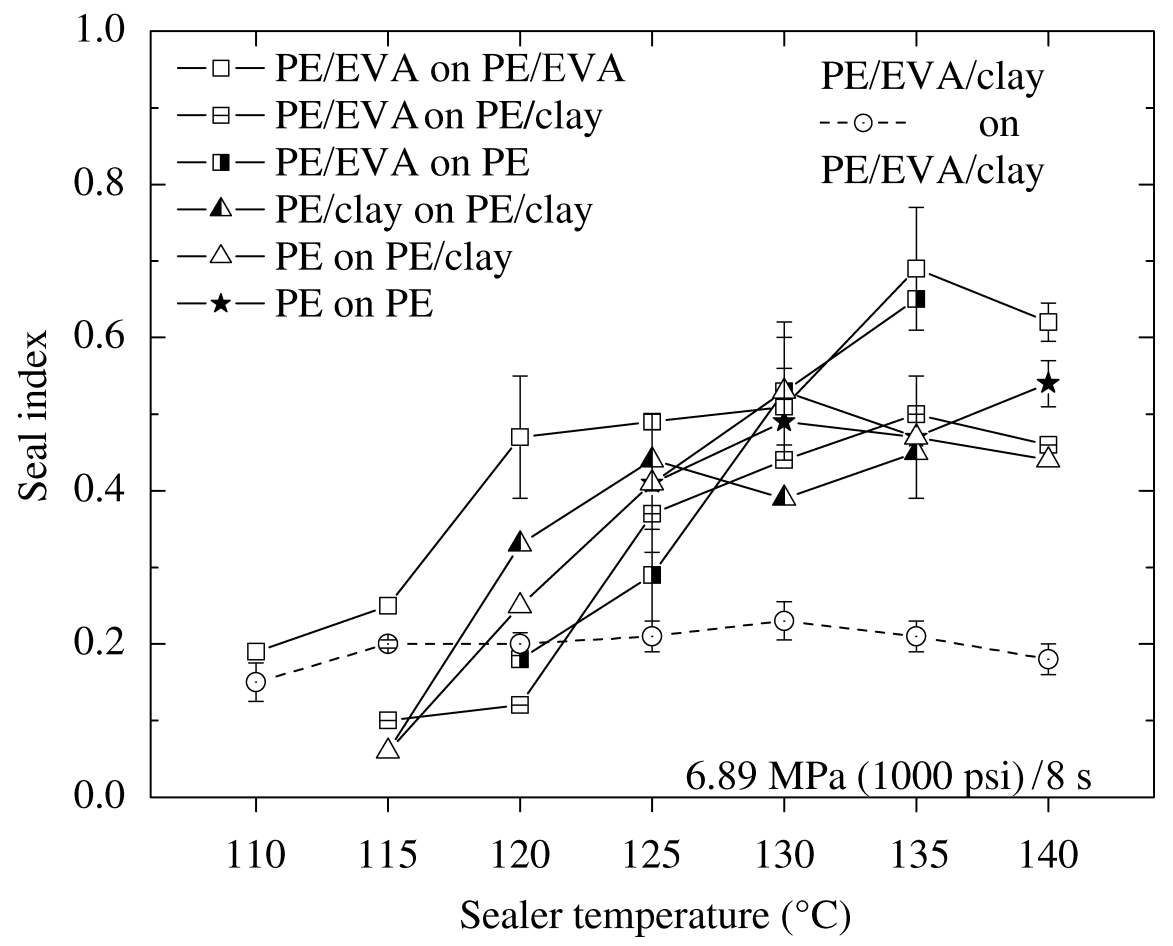

(a)

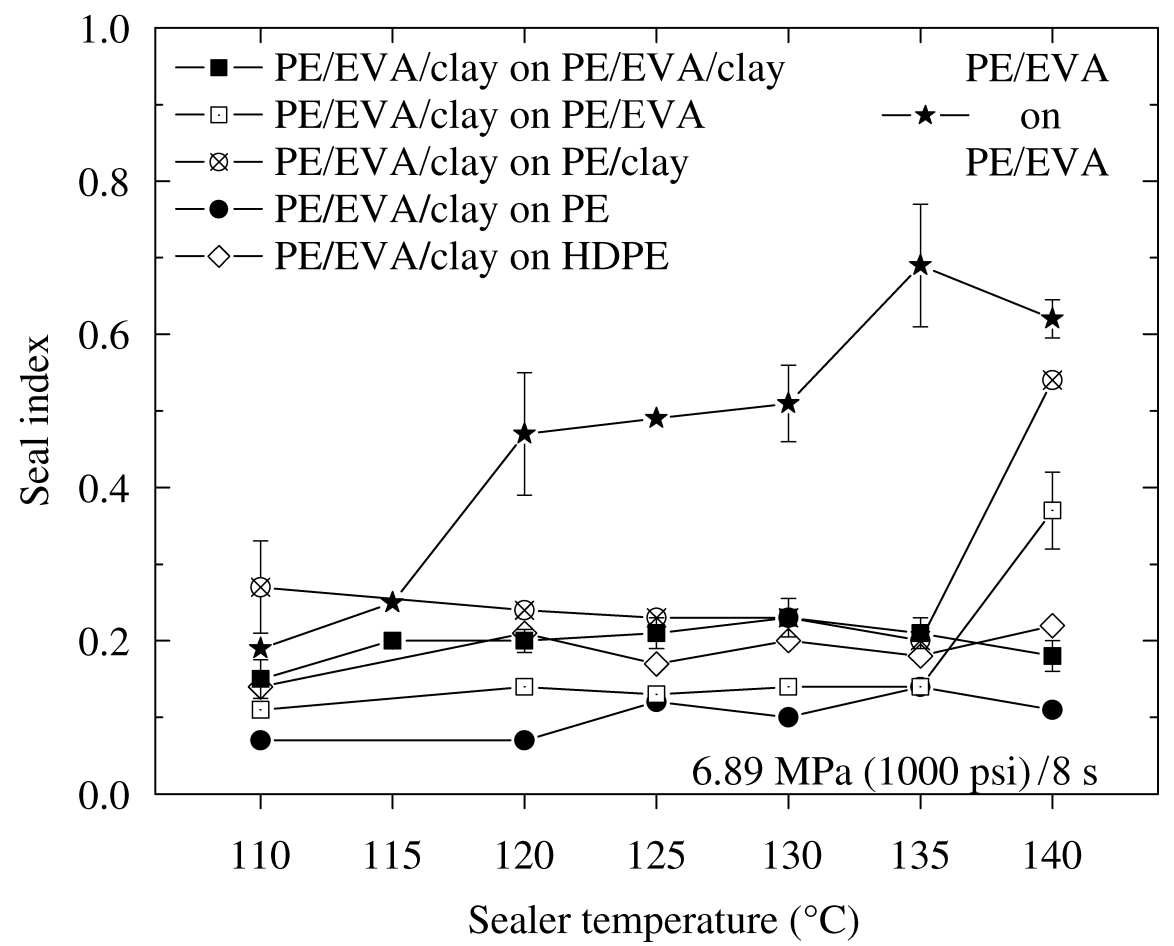

(b)

Figure 6. Seal index plots for 25.4-mm-wide flat seals (6.89 MPa (1000 psi)/8 s, seal strengths and materials from Figs 4 and 5). Introduction of EVA-copolymer alone or nanocomposite (clay nanofiller) alone have a small effect on the plateau seal index. On the contrary, the seal index of all PE/EVA/clay seals is substantially different $(0.1-0.3$, peelable, across all systems and over a broad range of sealing temperatures); this observation strongly suggests a synergistic effect of the EVA-copolymer and the montmorillonite (clay) filler. 


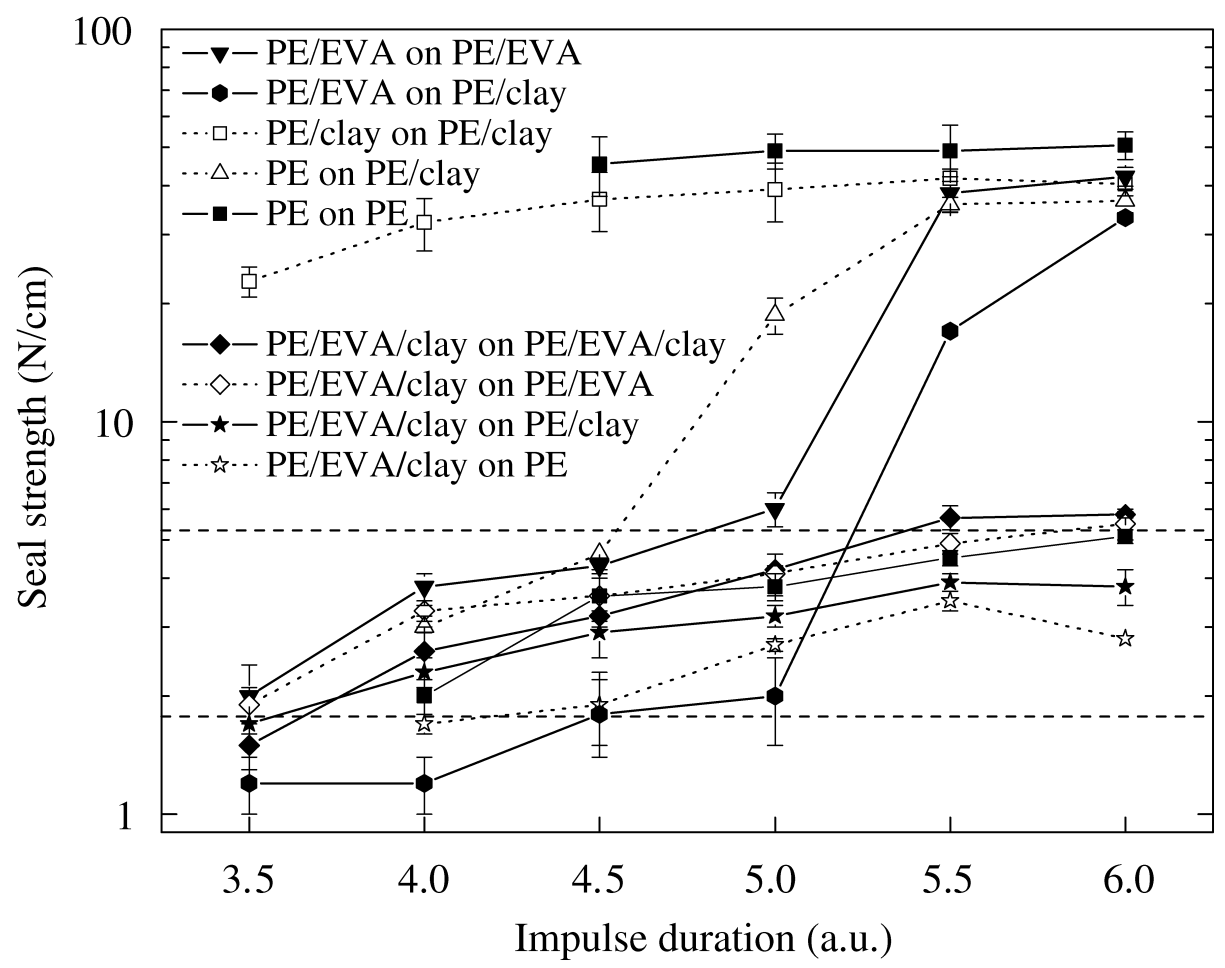

Figure 7. Seal strength for serrated seals (five parallel-line geometry, impulse thermal sealer, all sealants as in Figs 4 and 5). The temperature at the seal interface increases with the impulse duration, albeit differently for each film (see Note 2). The same seal trends (fused $v s$. peelable) observed before at high pressures and long dwell times are reproduced here, despite the much shorter dwell times, the very low pressures, and the serrated seal geometry. It is noteworthy that all PE/EVA/clay seals still remain peelable over the whole range of impulses (range of sealing temperature) independently of the second surface of the seal.

low pressures, with the interface most often not reaching equilibrium, especially for thick films [21].

It is clear that the same trends (fused or peelable seals) are observed for the serrated impulse heat seals (Fig. 7), as were observed for the same sealant combinations for well-equilibrated flat seals (Figs 4 and 5). Namely, peelable seals are also produced here across the complete range of heat impulses used (see Note 3). In addition, the failure modes for the various film combinations have the same trends as before (Table 2). Again, PE/EVA/clay forms peelable seals across the range of impulse seals, independent of the material sealed onto, while no other sealant shows the same behavior. The unusually high seal strengths of the fused seals are due to the fact that the sealed area $(10 \mathrm{~mm}$ total seal width) is defined by a serrated seal profile of five parallel lines, each $2 \mathrm{~mm}$ in width, which results in ten seal/no-seal 'interfaces' that introduce a substantial rise in the seal strength (see Note 3). The use of serrated seal patterns is an extremely common practice to strengthen heat seals in commercial applications. The fact that even these serrated seals of the PE/EVA/clay nanocomposite sealants remain peelable further attests that peelability is intrinsic to these nanocomposites. 


\subsubsection{PE/EVA/Clay Nanocomposite Sealants of Varied Compositions}

For both sets of experiments above, PE/EVA/clay nanocomposite sealants were of the same formulation and composition, namely, the same sealant matrix (LLDPE/LDPE) containing an 18\% vinyl acetate LDPE copolymer and $6 \mathrm{wt} \%$ dimethyl-dioctadecyl montmorillonite (via a MAH-graft-LLDPE masterbatch). To further test the generality of the peelable behavior observed above, another series of blown films of sealants coextruded on HDPE were tested, where the sealant formulation was varied as follows: containing two different PE sealants (LLDPE/LDPE blends of similar specifications but from different commercial sources), two different LDPE-VA-copolymers (with $18 \%$ and $9 \%$ of vinyl acetate comonomer) at two different copolymer loadings ( $30 \%$ and $60 \% \mathrm{w} / \mathrm{w}$ EVA-copolymer to PE sealant), and two different loadings of organo-montmorillonite (4 wt $\%$ and $2 \mathrm{wt} \% \mathrm{mmt}$ inorganic loading in the nanocomposites). Seals were made using an ASTM compliant Sentinel heat sealer, operated at the ASTM standard sealing conditions of $0.2758 \mathrm{MPa}$ (40 psi) pressure and $0.5 \mathrm{~s}$ dwell time. The results for these seals are summarized in Fig. 8. Despite the large variations in materials, formulations, and compositions the same sealing trends as before are also observed here.

Specifically, as shown in Fig. 8, for those PE/EVA sealants containing no montmorillonite nanofillers, fused seals are formed for sealer temperatures above $90^{\circ} \mathrm{C}$, independent of sealant composition. In contrast, the seals of the montmorillonitecontaining nanocomposite sealants (PE/EVA/clay) become peelable in all cases, and when a reduced loading of nanofiller $(2 \mathrm{wt} \%)$ is used the seal strengths increase, remaining below but close to $5.3 \mathrm{~N} / \mathrm{cm}$ [44]. The $4 \mathrm{wt} \%$ montmorillonite nanocomposite sealants result in a lower strength peelable heat seal. As before, when clay nanofiller and EVA are simultaneously present in the sealant, peelable seals were formed over a broad range of seal temperatures. With respect to this latter point, the nanocomposite sealants were also compared with a commercial grade $\mathrm{PE} / \mathrm{EVA}$ sealant, to which polybutylene (PB) was added to introduce peelability (sample K, Fig. 8). This optimized formulation shows only a $10^{\circ} \mathrm{C}$ range for peelable seals (about $105-115^{\circ} \mathrm{C}$ ) which is substantially narrower than what can be achieved by the nanocomposites. Finally, as shown here, this peelable behavior is highly reproducible across variations in materials specifications and sealant compositions, with the only strong dependence being on the filler loading (Fig. 8). Such variations in sealant formulation offer opportunities for further performance optimization of these nanocomposite materials, but this topic is beyond the scope of the present study.

\subsection{Origins of Seal Performance for Nanocomposite Sealants}

\subsubsection{Summary of Findings and Observations}

Before proceeding to a detailed investigation and a discussion of the mechanisms and origins of seal performance and failure, we outline the main experimental observations: 


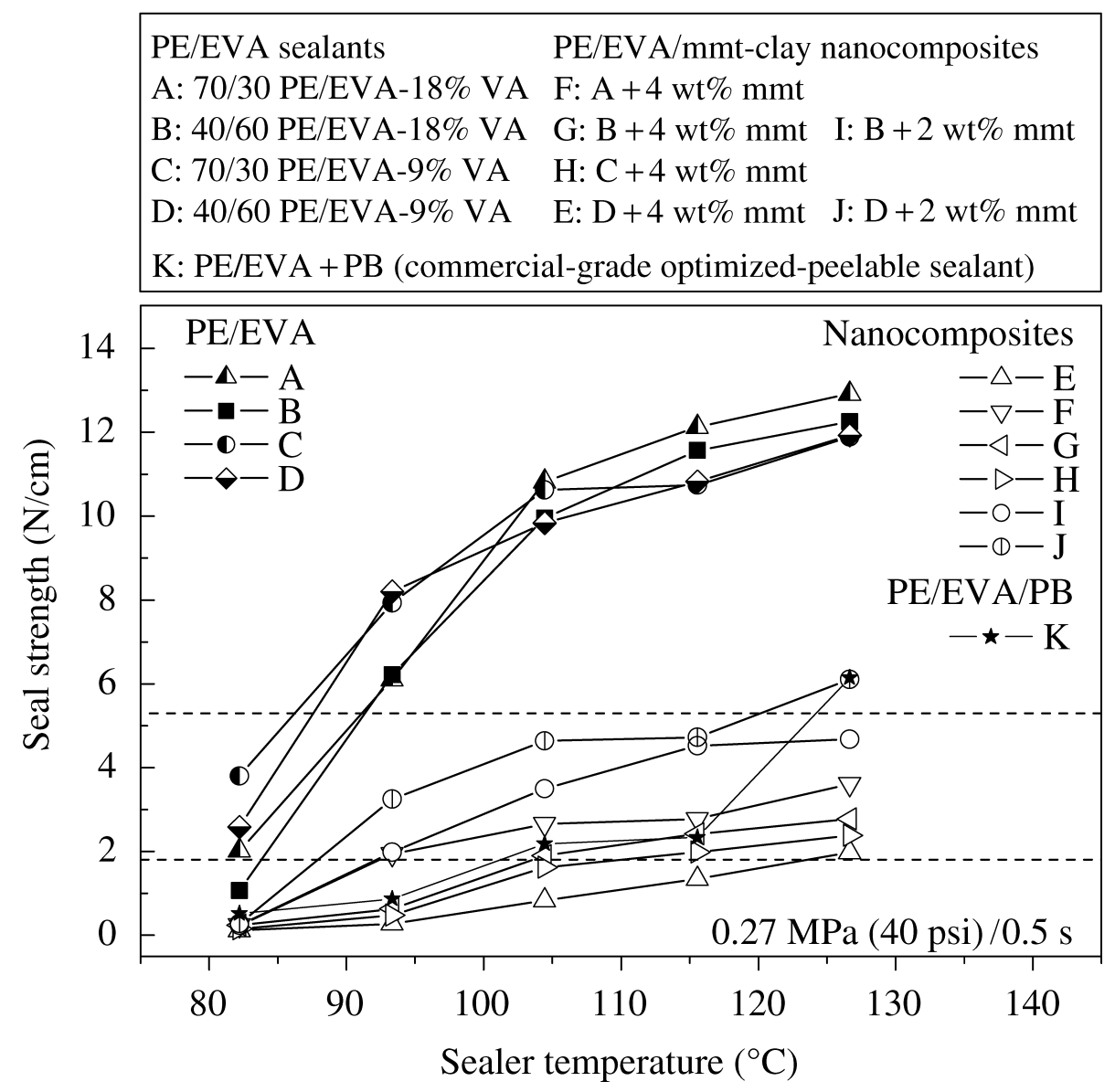

Figure 8. Seal strength dependence on the sealant composition (HDPE/sealant blown films; Sentinel; $25.4 \mathrm{~mm}$ flat seals; $0.27 \mathrm{MPa}$ (40 psi)/0.5 s [38]). (A-D) Unfilled PE/EVA sealants with $18 \%$ or 9\% vinyl acetate EVA. (F-J) Nanocomposite sealants (4 wt\% mmt, triangles, F-H; $2 \mathrm{wt} \% \mathrm{mmt}$, circles, I-J). (K) Commercial peelable sealant with polybutylene. The seal strengths lump together in three groups for unfilled blends (fused above $90^{\circ} \mathrm{C}$ ), peelable with higher seal strengths $(2 \mathrm{wt} \% \mathrm{mmt}$ nanocomposites), and peelable with lower seal strengths (4 wt\% $\mathrm{mmt}$ nanocomposites).

1. Hermetic and peelable seals are formed by the nanocomposite sealant that contains EVA-copolymer. Sealants that do not contain both EVA-copolymer and montmorillonite (clay) nanofillers behave qualitatively similar to the typical commercial polyethylene-based sealants. Thus, there exists a synergistic effect between the EVA-copolymer and the montmorillonite nanofiller.

2. The range of sealing temperatures that produces peelable seals is remarkably broad; about $30-40^{\circ} \mathrm{C}$ for the nanocomposites, compared to only $2-5^{\circ} \mathrm{C}$ for the respective ordinary sealants and to $10^{\circ} \mathrm{C}$ for $\mathrm{PB}$-containing peelable sealants.

3. The peelable character of the nanocomposite heat seals is completely independent of sealing method, ranging from ultra-high pressures and long dwell times, to ASTM standard values, to short heatings at low pressures (impulse sealer). 
Since changes in the sealing method affect mostly the temperature equilibration of the seal interface, this observation is equivalent to the one above (i.e., equivalent to achieving a peelable seal over a broad range of sealing temperatures).

4. In addition, the peelable character of the nanocomposite sealants is quite insensitive to variations in the formulation of the nanocomposite sealant, and markedly independent of the other surface of the seal (manifested for seals on self, on unfilled PE sealant, on nanocomposite sealants with no EVA-copolymer and on HDPE). Thus, indicating again that the necessary component is the coexistence of EVA-copolymer and clay-nanofiller ( $c f$. first observation above) and that the underlying mechanism relates to the nature of the nanocomposite sealant, rather than to the sealing conditions ( $c f$. second and third observations above).

\subsubsection{Characterization of Fractured Seal Surfaces and Proposed Mechanism}

The fracture surfaces of broken heat seals were characterized, in order to unveil the mechanism responsible for the observed seal behavior. In particular, to trace the origins of the 'universal' peelability of the PE/EVA/clay nanocomposite sealants, which is manifested across a very broad sealing temperature range and independent of the second surface upon which it is heat-sealed. The fracture surfaces of various seals were characterized by attenuated total reflection Fourier transform infrared (ATR-FT-IR) spectroscopy and by environmental scanning electron microscopy (ESEM). The ATR-FT-IR spectra for the surface of the virgin (before heat sealing) sealant films are shown in Fig. 9, and the ATR-FT-IR spectra of the fracture surfaces from selected seals are shown in Fig. 10. The characteristic peaks for the EVA-copolymer are located at $1742 \mathrm{~cm}^{-1}$ and $1245 \mathrm{~cm}^{-1}$, due to the ester group of the vinyl acetate, and the IR signature of the montmorillonite layered-silicate is the $\mathrm{SiO}_{x}$ band located at 1000 to $1100 \mathrm{~cm}^{-1}$ (Fig. 9).

Focusing first on peelable seals formed when PE/EVA/clay nanocomposite sealants are sealed on neat PE films, the ATR-FT-IR spectra show traces of EVA and of clay on the PE side of the fracture surface, indicating that the fracture path was through the PE/EVA/clay nanocomposite (cohesive failure of the nanocomposite sealant (see Note 4)); this observation holds for seals formed both at low sealing temperature (Fig. 10, spectrum e) as well as at high sealing temperature (Fig. 10, spectrum f). In contrast, when PE/EVA sealant is used, there is no evidence of EVA-copolymer on the other side of the fractured seal (neither for peelable, Fig. 10, spectrum h, nor for fused seals, Fig. 10, spectrum c) indicating an interfacial (adhesive) failure of the seal. For PE/clay sealants, filler is detected on the other side of the seal (especially for fused seals, Fig. 10, spectrum b, and in much smaller amounts for peelable seals, Fig. 10, spectrum a), indicating a cohesive failure for fused PE/clay sealants. In absence of any kinetic effects - the long dwell time and high pressure assure that there are no diffusion or thermal equilibration limitations $[21,23]$ in these seals - these results demonstrate that fracture occurs 


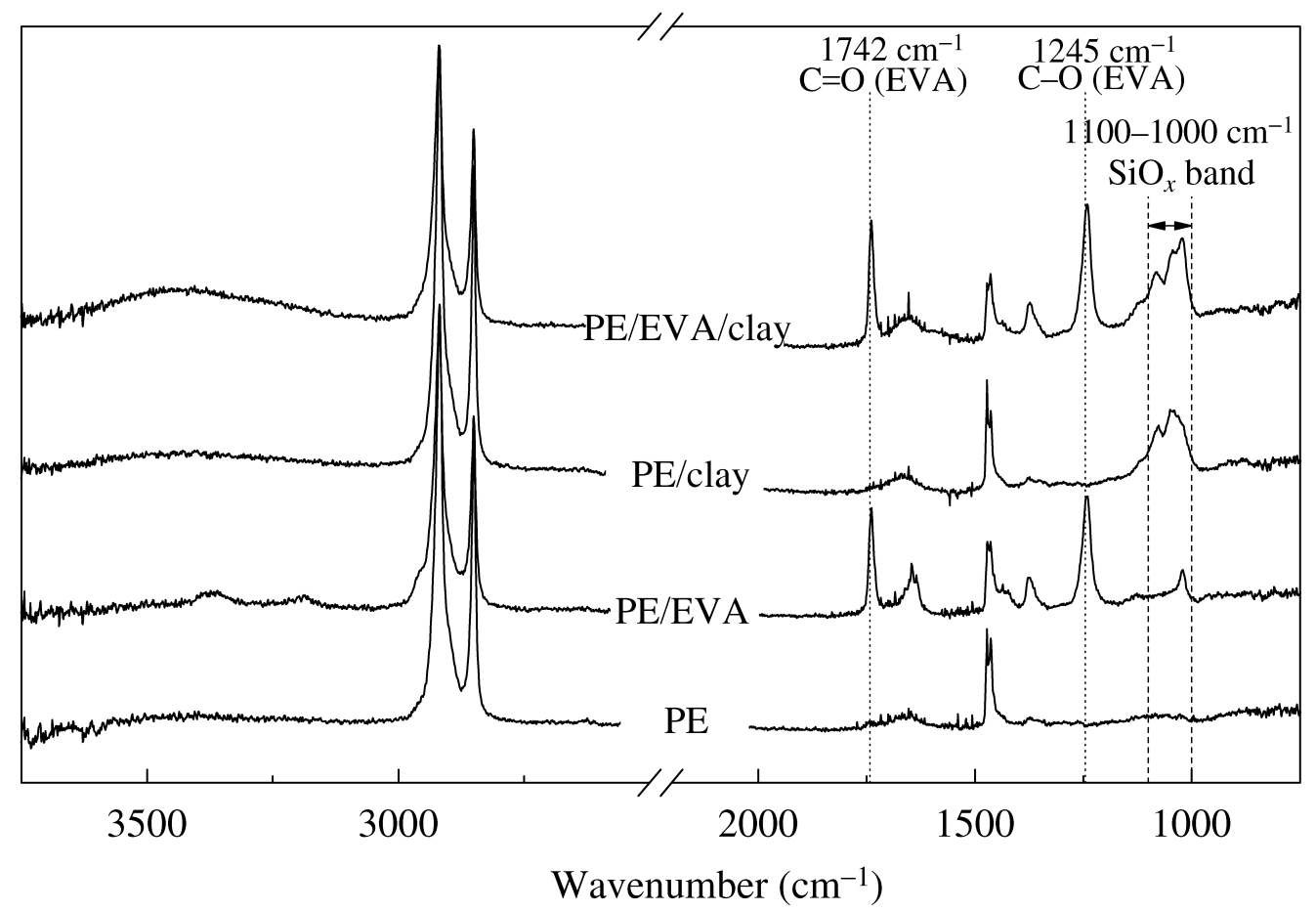

Figure 9. Attenuated Total Reflection Fourier Transform Infrared (ATR-FT-IR) spectra of the various sealant films used in this study. The materials are termed as per Fig. 4. The peaks at $1742 \mathrm{~cm}^{-1}$ and $1245 \mathrm{~cm}^{-1}$ are characteristic resonances for the ester group of EVA $(\mathrm{C}=\mathrm{O}$ and $\mathrm{C}-\mathrm{O}$, respectively), whereas the $1000-1100 \mathrm{~cm}^{-1}$ band corresponds to the $\mathrm{SiO}_{x}$ of the montmorillonite layered-silicate.

preferentially at the interfaces of the montmorillonite clay fillers (Fig. 10); they further suggest a weaker interface between PE and EVA/clay compared to the PE/clay interface (see Note 5), which seems, in turn, weaker than the PE/EVA interface. This last remark is qualitatively shown in the spectrum $\mathrm{g}$ of Fig. 10, where, in a peelable seal between PE/EVA and PE/clay, clay nanofillers are detected on the PE/EVA side whereas no EVA is detected on the PE/clay side. This ranking of interfacial strengths is also consistent with the respective seal strengths (shown in Figs 4, 5 and 7), as well as is in accord with considerations of how the nature of the copolymers (i.e., the polar VA and MAH comonomers, and the difference in branching between the MAH-graft-LLDPE and VA-random-LDPE) will affect the interfacial adhesion with the $\mathrm{SiO}_{x}$ surface of the fillers [46-49].

Further insights can be gained by direct observation of the fracture surfaces by environmental scanning electron microscopy (ESEM). Figure 11 compares the PE sides of the fracture surfaces from a PE/EVA seal on PE and from a PE/EVA/clay seal on PE. Since ESEM requires no metal coating of the imaged surface, a qualitative analysis of the surface elemental composition can also be done via EDS (Energy-Dispersive X-ray Spectroscopy). EDS records the characteristic energies of the emitted X-rays for the surface atom shell transitions when they interact with the primary scanning electron beam. The ESEM images of the fracture surfaces show much smoother fractured surfaces on the PE side from a PE/EVA on PE seal, compared to the PE side from a PE/EVA/clay on PE seal (Fig. 11, images a and b 


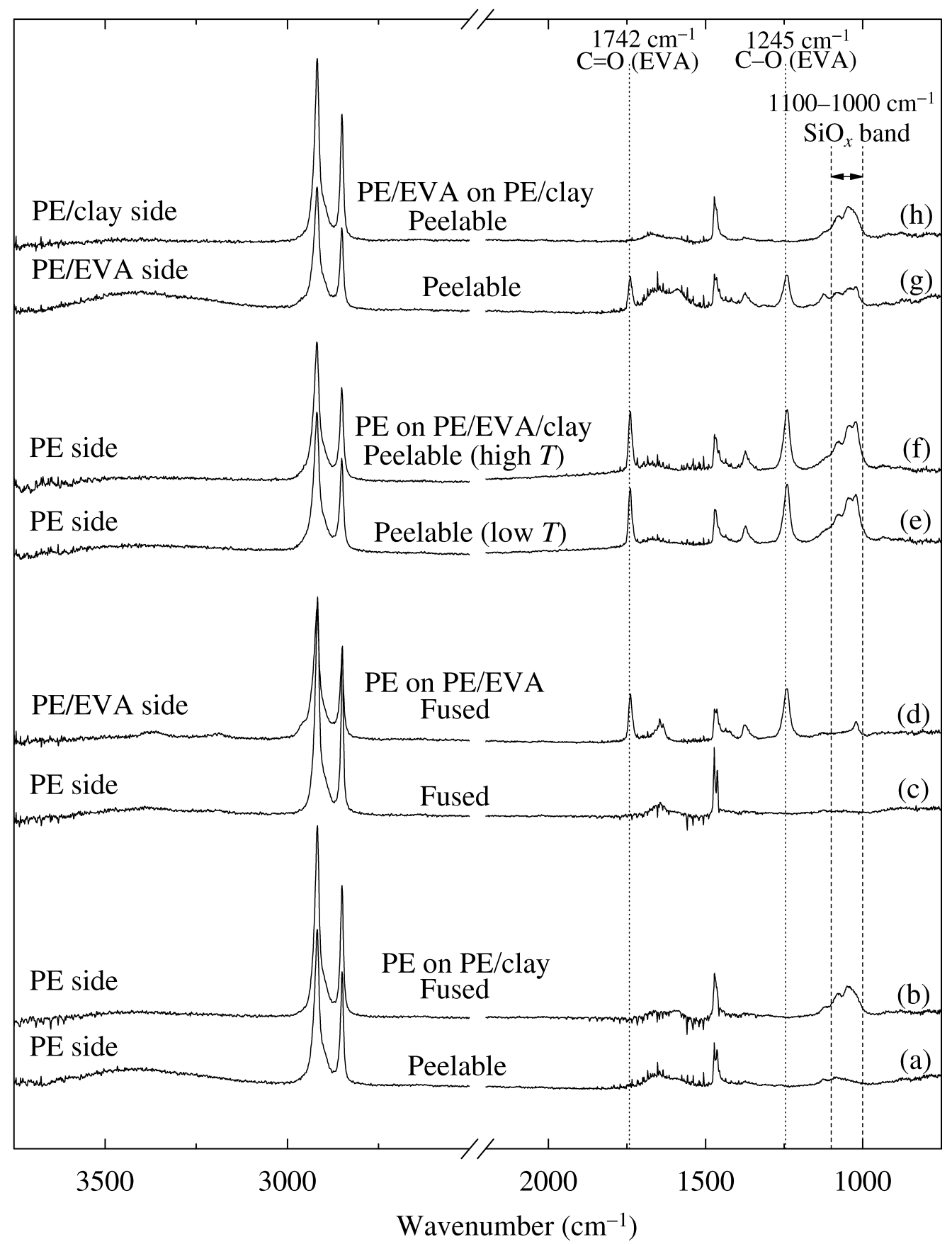

Figure 10. ATR-FT-IR spectra of fracture surfaces from selected broken flat seals (6.89 MPa (1000 psi)/8 s dwell; sealing temperature varies to show peelable or fused seals; spectra are from one $(\mathrm{a}, \mathrm{b}, \mathrm{e}, \mathrm{f})$ or both $(\mathrm{c}, \mathrm{d}$ and $\mathrm{g}, \mathrm{h}$ ) fracture seal surfaces; materials and seal strengths shown in Figs 4 and 5). For PE/EVA/clay nanocomposite sealants, mmt and EVA-copolymer are detected on the opposite side of the broken seal, indicating a general cohesive failure of the nanocomposite; absence of similar transfers in PE/clay and PE/EVA indicates that this behavior results from a synergy of EVA-copolymer and mmt nanofiller.

vs. images $\mathrm{c}$ and $\mathrm{d}$ ), despite the seal strength of PE on PE/EVA/clay being smaller $(2.7 \mathrm{~N} / \mathrm{cm}$, peelable seal) than that of PE on PE/EVA $(9.1 \mathrm{~N} / \mathrm{cm}$, weakly fused seal). Generally, a rougher fracture surface indicates a higher energy to break, since it 

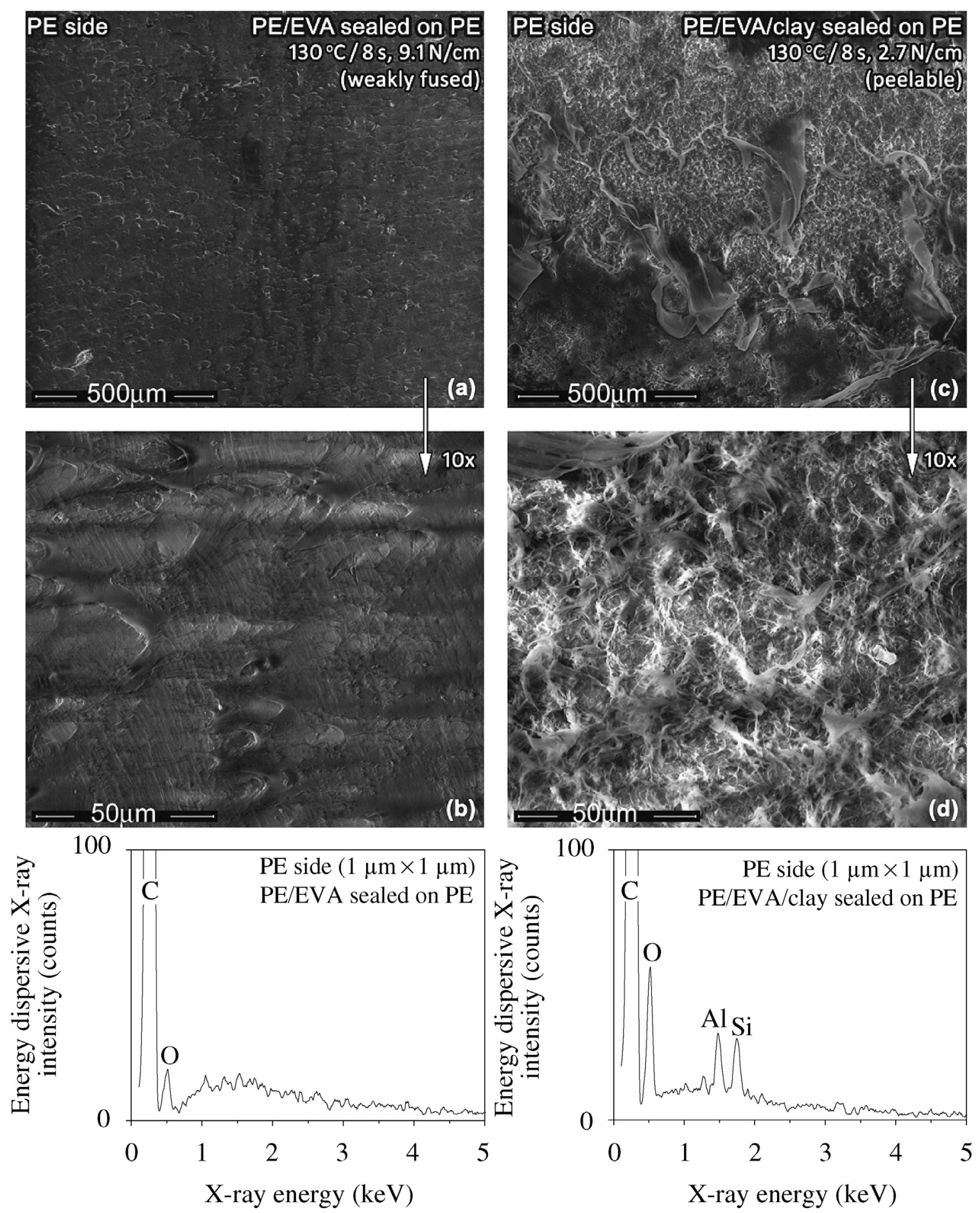

Figure 11. Secondary electron (topography) images (top) and corresponding energy-dispersive X-ray spectra (bottom) from environmental SEM of fracture seal surfaces: The PE side of PE/EVA sealed on PE (left) is relatively smooth and shows almost exclusively carbon on the surface. The PE side of PE/EVA/clay film sealed on PE (right) is much rougher despite the lower seal strength, and clearly shows oxygen, aluminum and silicon, denoting appreciable amounts of montmorillonite layered-silicate on the fracture surface. 
corresponds to a more tortuous crack propagation and larger effective fracture area. Thus a rougher fracture surface for the weaker seal clearly denotes that the cracks in PE/EVA/clay sealants deviate from straight propagation, so as to travel through weaker regions in the nanocomposite sealant [49], for example, interfaces between EVA and clay and/or interfaces between PE and EVA/clay. The crack propagation through these 'weaker' interfaces is demonstrated also by the ATR-FT-IR spectra (Fig. 10), and is consistent with the EDS spectra of the fracture surfaces (Fig. 11). On this latter point, since in both cases EDS spectra are collected from the PE side of the fracture seal, the $\mathrm{Si}$ and $\mathrm{Al}$ signals can only arise from the layered-silicate montmorillonite nanofiller when the PE/EVA/clay sealant undergoes a cohesive failure.

Thus, for all the data shown - seal strengths, ATR-FT-IR spectra, ESEM and EDS spectra - the results are consistent only when the interfacial strength increases from weakest between PE and EVA/clay, to weak between PE and clay, to stronger between PE and EVA, in agreement with theoretical and simulation considerations [46, 50-52]. Consequently, the origins of the peelable nature of this $\mathrm{PE} / \mathrm{EVA} /$ clay nanocomposite sealant can be traced to its cohesive failure, mediated by weak interfaces within the nanocomposite, as is schematically illustrated in Fig. 12. This mechanism supports a synergy of EVA-copolymer and montmorillonite nanofiller that can account for peelable heat seals for PE/EVA/clay nanocomposite sealants. In addition, this synergy naturally explains why this effect is general across various heat sealing methods, over a broad range of sealing temperatures and pressures, for varied sealant formulations, and independent of the nature of the opposite seal surface. Finally, given that peelability is afforded by design of the filler/polymer interfaces, these nanocomposites can naturally accommodate other additives for improved processing (anti-slip agents, stabilizers, etc.) or functionality (antimicrobial, food-quality additives, etc.) [42].

\section{Conclusions}

Novel polyethylene-based nanocomposite sealants were designed and investigated in this study, based on montmorillonite nano-reinforcement and ethyl vinyl acetate (EVA) copolymer addition to ordinary polyethylene sealants. The focus was on producing nanocomposite sealant films that form hermetic but peelable (easyopen) heat-seals, over a very broad range of sealing temperatures, times and pressures. This performance was achieved through a synergy of montmorillonite nanofillers and EVA-copolymer additive, that resulted in a general cohesive failure behavior. This resulted in peelable heat seals independent of sealing method (ranging from high pressure and $8 \mathrm{~s}$ dwell time, to low pressures and sub-second dwell times) over a very broad range of seal temperatures $\left(30-40^{\circ} \mathrm{C}\right.$ range for the nanocomposites, instead of $2-5^{\circ} \mathrm{C}$ for neat $\mathrm{PE}$ sealants, or $10^{\circ} \mathrm{C}$ for $\mathrm{PB}$-containing peelable sealants), as well as markedly independent of the seal substrate (on itself, on typical PE sealants and on HDPE). The origins and the mechanism of 

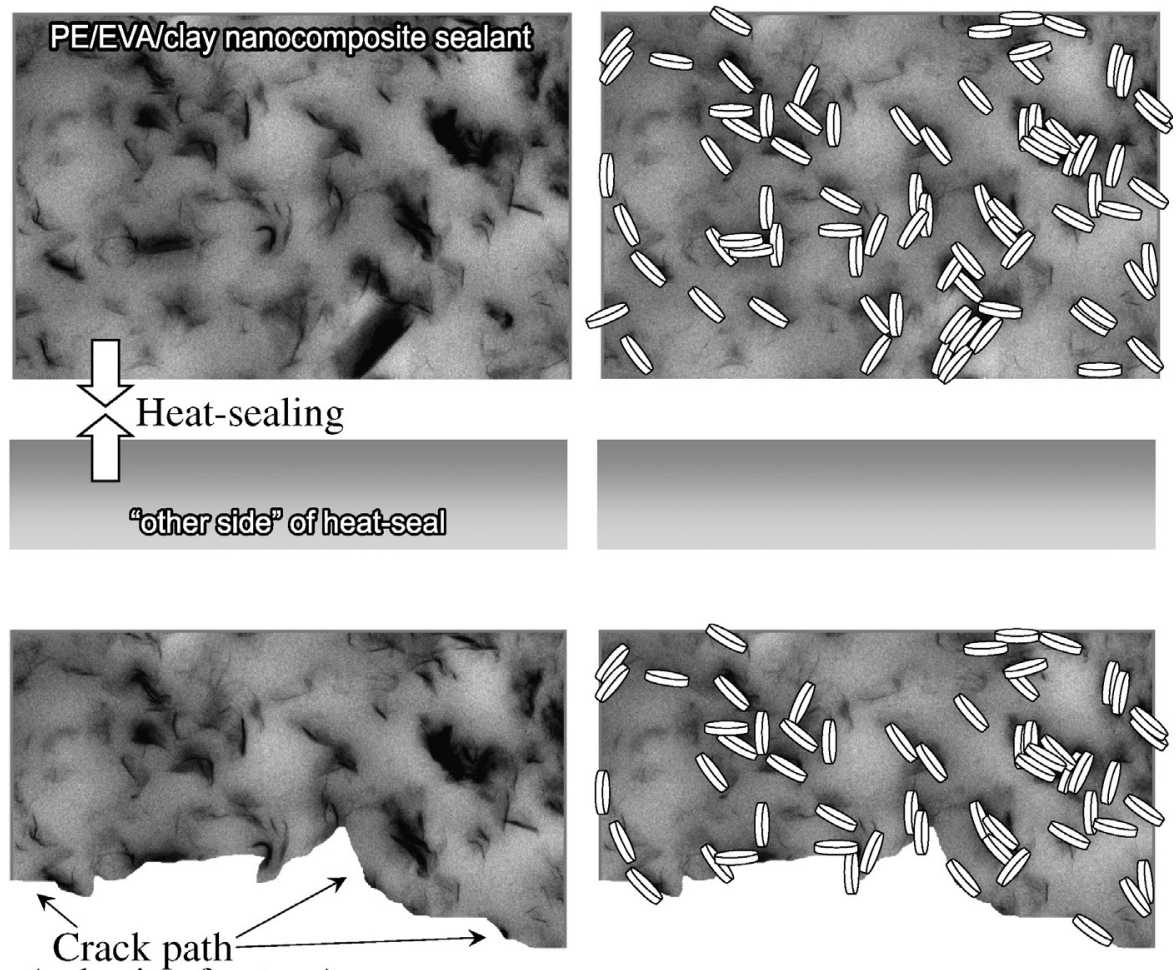

\section{(cohesive fracture)}
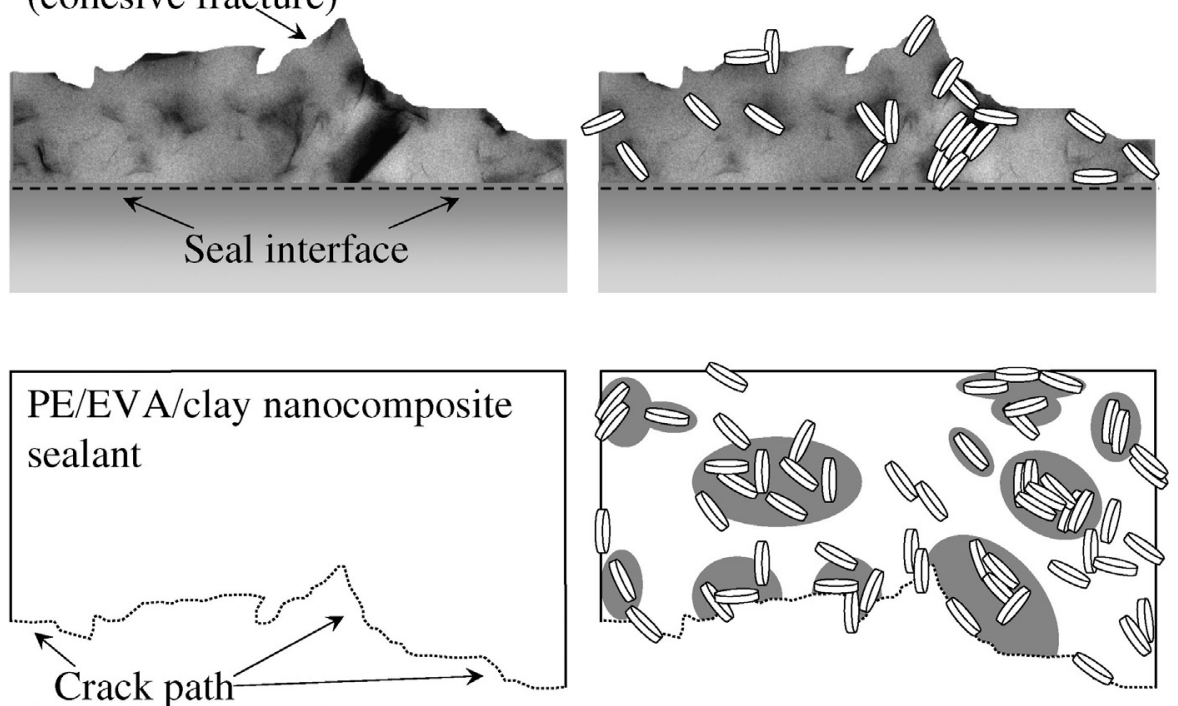

(cohesive fracture)

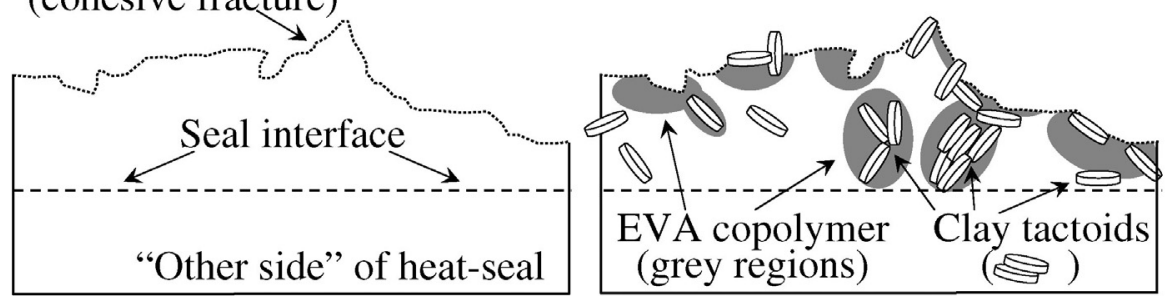

Figure 12. A schematic representation of the proposed mechanism that accounts for the peelable heat seals formed by PE/EVA/clay nanocomposites. An incorporation of selected weak interfaces in the nanocomposite is employed to promote cohesive failure of the nanocomposite sealant. These weak interfaces become least-effort paths for crack propagation upon seal fracture. Such an approach can enable peelable heat seals across a broad range of sealing conditions and sealant formulations, as demonstrated by the data in this study. 
this behavior were traced, through spectroscopic and microscopy analyses, to the weak EVA/montmorillonite interfaces, that promote crack propagation within the nanocomposite sealant. Consequently, variations in the nanocomposite sealant formulation - such as altering the PE type, the EVA-copolymer type and concentration, and the nanofiller loading - do not impact the sealing and peeling behavior of these systems, as demonstrated here. In all, such polyethylene-based nanocomposite sealant films offer unprecedented opportunities for commercial application in the plastics packaging field, since they allow for peelable heat seals with unmatched tolerances in sealing conditions, sealant formulation, and over a very broad range of sealing temperatures.

\section{Acknowledgements}

Financial support and generous donations of materials by Kraft Global Foods are gratefully acknowledged. Additional financial support by the National Science Foundation (Grant No. DMR-0602877, an MWN/Polymer Division grant) was provided to G. P. and E. M., and by the Penn State University Agricultural Experimental Station to P. S. and M. M. J. G.

\section{Notes}

1. The increase of the $d_{001}$ spacing upon EVA addition is accompanied by an increase in diffracted intensity and a decrease of the full width at half maximum (Fig. 1). The XRD patterns are from samples with varied clay content and without an internal reference to normalize the intensities [41]. The increase in intensity and the sharpening of the diffracted peak for the PE/EVA/clay system is not due to an increased number of diffracting moieties (i.e., more intercalated montmorillonite tactoids, which is very highly improbable since the two masterbatches have $25 \mathrm{wt} \%$ montmorillonite, whereas the three nanocomposites have only $4 \mathrm{wt} \%$ of montmorillonite). Rather, the sharper and more intense diffraction peak is due to tactoid alignment (i.e., fillers are flow-aligned in the blown films, but randomly oriented in the bulk mastebatches) and due to an improvement in coherence length (i.e., better parallel stacking of mmt in PE/EVA) which also accounts for the appearance of strong 002 and 003 reflections in this system. TEM (Fig. 2) shows very similar dispersions for all three nanocomposites at the micrometer scale (i.e., similar montmorillonite tactoid dispersion).

2. Throughout this paper the temperature of heat sealing is described by two different parameters: The Sealing Temperature, which denotes the actual temperature at the sealing interface, and the Sealer Temperature, which is the temperature of the sealing apparatus (also commonly referred to as the Platen Temperature in engineering and industrial texts) and must be used when the sealing temperature is unknown (i.e., when temperature equilibration is doubtful). For methods 
that employ long dwell times, e.g., more than $1 \mathrm{~s}$ for the films used here, the sealer temperature and the sealing temperature are the same.

3. Since the temperature, dwell time, or pressure cannot be recorded for the impulse sealer, it is extremely difficult to quantitatively compare the numbers from Fig. 6 with the numbers reported in Figs 4 and 5. Translation of the impulse sealer's 'dial indicator' to 'temperature at the seal interface' necessitates an exact knowledge of each film's thermal conductivity and heat capacity, as well as the time-temperature profile of the impulse. Translation of the seal strength from the serrated 5-line seal, as defined by the impulse sealer, into seal strength for a flat seal necessitates knowledge of the strength of the ten interfaces of the serration. None of these informations is known, or easily measured, and the impulse sealer data are presented here as a qualitative, but very definitive, evidence of sealing behavior being independent of heat sealing conditions and apparatus.

4. For some of the specimens studied by ATR-FT-IR there was a poly(vinyl alcohol) layer added between the sealants and the HDPE substrate; the absence of any trace of poly(vinyl alcohol) from all ATR-FT-IR spectra definitively indicated that no delamination of the sealant from the substrate occured.

5. The PE/clay interface in these systems - which were produced via MAHgraft-PE masterbatch — includes a high percentage of functionalized MAHgraft-PE.

\section{References}

1. S. S. Ray and M. Okamoto, Prog. Polym. Sci. 28, 1539-1641 (2003).

2. M. Alexandre and P. Dubois, Mater. Sci. Eng. R 28, 1-63 (2000).

3. E. P. Giannelis, R. Krishnamoorti and E. Manias, Adv. Polym. Sci. 138, 107-147 (1999).

4. J. Zhang, E. Manias and C. A. Wilkie, J. Nanosci. Nanotechnol. 8, 1597-1615 (2008).

5. H. Dodiuk, I. Belinski, A. Dotan and S. Kenig, J. Adhesion Sci. Technol. 20, 1345-1355 (2006).

6. E. Manias, Nature Mater. 6, 9-11 (2007).

7. J. W. Gilman, C. L. Jackson, A. B. Morgan, E. Manias, E. P. Giannelis, M. Wuthenow, D. Hilton and S. H. Phillips, Chem. Mater. 12, 1866-1873 (2000).

8. J. Zhu, F. M. Uhl, A. B. Morgan and C. A. Wilkie, Chem. Mater. 13, 4649-4654 (2001).

9. J. W. Gilman, Appl. Clay Sci. 15, 31-49 (1999).

10. M. C. Costache, D. Wang, M. J. Heidecker, E. Manias and C. A. Wilkie, Polym. Adv. Technol. 17, 272-280 (2006).

11. M. C. Costache, M. J. Heidecker, E. Manias, G. Camino, A. Frache, G. Beyer, R. K. Gupta and C. A. Wilkie, Polymer 48, 6532-6545 (2007).

12. D. M. Lincoln, R. A. Vaia and R. Krishnamoorti, Macromolecules 37, 4554-4561 (2004).

13. D. M. Lincoln, R. A. Vaia, Z. G. Wang, B. S. Hsiao and R. Krishnamoorti, Polymer 42, 9975-9985 (2001).

14. D. M. Lincoln, R. A. Vaia, Z. G. Wang and B. S. Hsiao, Polymer 42, 1621-1631 (2001).

15. K. E. Strawhecker and E. Manias, Macromolecules 34, 8475-8482 (2001). 
16. K. E. Strawhecker and E. Manias, Chem. Mater. 12, 2943-2949 (2000).

17. J. K. Pandey, K. R. Reddy, A. P. Kumar and R. P. Singh, Polym. Degrad. Stabil. 88, 234-250 (2005).

18. M. Darder, P. Aranda and E. Ruiz-Hitzky, Adv. Mater. 19, 1309-1319 (2007).

19. J. K. Pandey, A. P. Kumar, M. Misra, A. K. Mohanty, L. T. Drzal and R. P. Singh, J. Nanosci. Nanotechnol. 5, 497-526 (2005).

20. S. S. Ray and M. Bousmina, Prog. Mater. Sci. 50, 962-1079 (2005).

21. P. Meka and F. C. Stehling, J. Appl. Polym. Sci. 51, 89-103 (1994).

22. F. C. Stehling and P. Meka, J. Appl. Polym. Sci. 51, 105-119 (1994).

23. C. Mueller, G. Capaccio, A. Hiltner and E. Baer, J. Appl. Polym. Sci. 70, 2021-2030 (1998).

24. J. W. Rinker, Paper, Film \& Foil Converter 52, 71-75 (1978).

25. N. Z. Qureshi, E. V. Stepanov, G. Capaccio, A. Hiltner and E. Baer, Macromolecules 34, 1358-1364 (2001).

26. N. Z. Qureshi, M. Rogunova, E. V. Stepanov, G. Capaccio, A. Hiltner and E. Baer, Macromolecules 34, 3007-3017 (2001).

27. E. Manias, A. Touny, L. Wu, K. Strawhecker, B. Lu and T. C. Chung, Chem. Mater. 13, 3516-3523 (2001).

28. J. Zhang and C. A. Wilkie, Polym. Deg. Stabil. 80, 163-169 (2003).

29. J. Golebiewski, A. Rozanski, J. Dzwonkowski and A. Galeski, Europ. Polym. J. 44, 270-286 (2008).

30. J. M. Lagaron, L. Cabedo, D. Cava, J. L. Feijoo and R. Gavara, Food Additives and Contaminants 22, 994-998 (2005).

31. Y. Zhong and D. D. Kee, Polym. Eng. Sci. 45, 469-477 (2005).

32. K. H. Wang, C. M. Koo and I. J. Chung, J. Appl. Polym. Sci. 89, 2131-2136 (2003).

33. K. D. Min, M. Y. Kim, K. Choi, J. H. Lee and S. Lee, Polym. Bull. 57, 101-108 (2006).

34. K. C. Cole, F. Perrin-Sarazin and G. Dorval-Douville, Macromol. Symp. 230, 1-10 (2005).

35. E. Jacquelot, E. Espuche, J.-F. Gerard, J. Duchet and P. Mazabraud, J. Polym. Sci. B: Polym. Phys. 44, 431-440 (2005).

36. C. C. Hwo, W. J. Graff and J. W. Secrist, J. Plastics Film \& Sheeting 11, 279-289 (1995).

37. F. P. La Mantia, N. T. Dintcheva, G. Filippone and D. Acierno, J. Appl. Polym. Sci. 102, 4749-4758 (2006).

38. ASTM F2029 Standard Practices for Making Heatseals for Determination of Heatsealability of Flexible Webs as Measured by Seal Strength, in: Annual Book of ASTM Standards, American Society for Testing and Materials, Vol. 15.10 (2008) (DOI: 10.1520/F2029-08); ASTM F88 Standard Test Method for Seal Strength of Flexible Barrier Materials, in: Annual Book of ASTM Standards, American Society for Testing and Materials, Vol. 15.10 (2007) (DOI: 10.1520/F0088-07).

39. Z. M. Wang, T. C. Chung, J. W. Gilman and E. Manias, J. Polym. Sci. B: Polym. Phys. 41, 3173-3187 (2003).

40. E. Manias, H. Chen, R. Krishnamoorti, J. Genzer, E. J. Kramer and E. P. Giannelis, Macromolecules 33, 7955-7966 (2000).

41. M. Zanetti and L. Costa, Polymer 45, 4367-4373 (2004).

42. P. Songptiya, M. M. Jimenez-Gasco and E. Manias, in preparation.

43. V. K. Stokes, Polym. Eng. Sci. 29, 1310-1324 (1989).

44. D. Dixon, A. A. Crangle and R. Mcilhagger, J. Appl. Med. Polym. 6, 30-34 (2002).

45. M. Tanniru, Q. Yuan and R. D. K. Misra, Polymer 47, 2133-2146 (2006).

46. E. Manias, G. Hadziioannou and G. ten Brinke, J. Chem. Phys. 101, 1721-1724 (1994).

47. R. A. Vaia and E. P. Giannelis, Macromolecules 30, 8000-8009 (1997). 
48. E. Manias, G. Polizos, H. Nakajima and M. J. Heidecker, in: Flame Retardant Polymer Nanocomposites, C. Wilkie and A. Morgan (Eds), Chap. 2. Wiley, Hoboken, NJ (2007).

49. W. J. Boo, L. Sun, G. L. Warren, E. Moghbelli, H. Pham, A. Vlearfield and H.-J. Sue, Polymer 48, 1075-1082 (2007).

50. V. Kuppa, S. Menakanit, R. Krishnamoorti and E. Manias, J. Polym. Sci. B: Polym. Phys. 41, 3285-3298 (2003).

51. E. Manias and V. Kuppa, Europ. Phys. J. E 8, 193-199 (2002).

52. V. Kuppa and E. Manias, J. Chem. Phys. 118, 3421-3429 (2003). 